\title{
DEBATE CONSTITUCIONAL EN EL MARCO DE LA ACTUALIZACIÓN DEL MODELO ECONÓMICO CUBANO
}

\author{
Constitutional Debate \\ on Updating the Cuban \\ ECONOMIC MODEL
}

\section{Debate constitucional NO MARCO DA ATUALIZAÇÃO DO MODELO ECONÔMICO CUBANO}

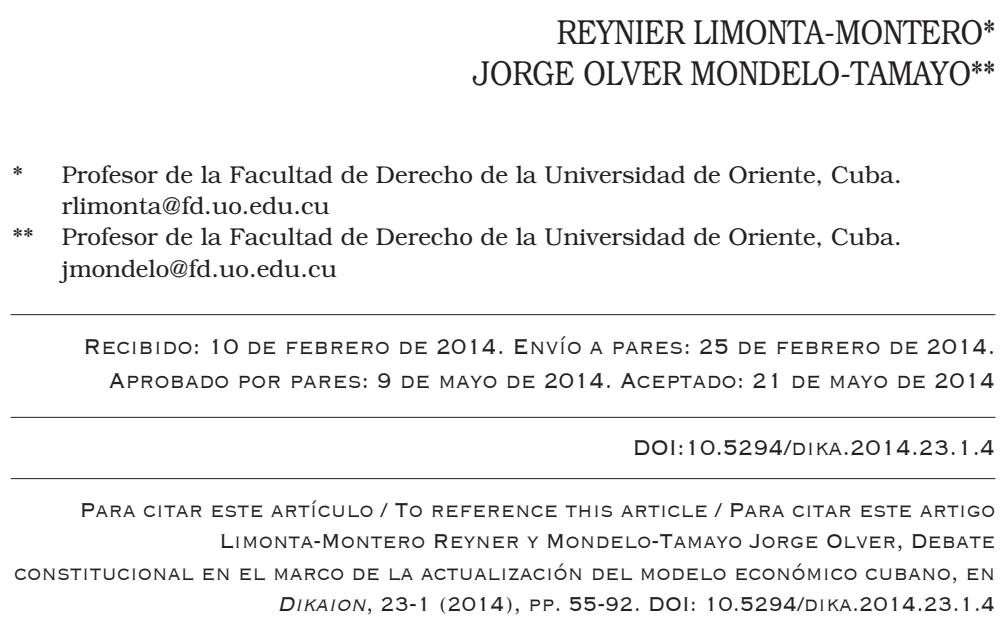




\section{RESUMEN}

El presente trabajo tiene su génesis en la falta de amparo constitucional de las propuestas en la actualización del modelo económico cubano. Por ello, el objetivo general de la investigación radica en fundamentar, a partir de un estudio doctrinal contextualizado sobre los postulados de la Constitución Económica, la necesidad de cambios constitucionales de diversa naturaleza en Cuba, que permitan el respaldo constitucional de las transformaciones que se vienen realizando en el país como parte de la actualización del modelo económico.

\section{PALABRAS ClaVe:}

Constitución económica, reforma constitucional, orden económico constitucional. 


\begin{abstract}
This paper has its genesis in the absence of constitutional protection in the proposals for updating the Cuban economic model. The overall objective of the research is to substantiate, through a contextualized doctrinal study on the principles of the economic order established in the constitution, the need for various constitutional amendments in Cuba that would provide constitutional backing for the changes taking place in the country as part of the bid to update its economic model.
\end{abstract}

\title{
KEY WORDS:
}

Economic constitution, constitutional amendment, constitutional economic order. 


\section{RESUMO}

O presente trabalho tem sua gênese na falta de amparo constitucional das propostas na atualização do modelo econômico cubano. Por isso, o objetivo geral da pesquisa radica em fundamentar, a partir de um estudo doutrinal contextualizado sobre as premissas da Constituição Econômica, a necessidade de mudanças constitucionais de diversa natureza em Cuba, que permitam o respaldo constitucional das transformações que vêm sendo realizadas no país como parte da atualização do modelo econômico.

\section{PALAVRAS-CHAVE:}

Constituição econômica, reforma constitucional, ordem econômico-constitucional. 
SUMARIO: PROEMIO NECESARIO; 1. CONSTRUYENDO UNA HISTORIA. CONSTITUCIÓN SOCIALISTA DE 1976; 2. UNA REFORMA NECESARIA. LA CONSTITUCIÓN ANTE LOS EMBATES DEL PERIODO ESPECIAL; 3. LA CONSTITUCIÓN ECONÓMICA DE 1976. ENTRE LA REFORMA Y LA CONSTITUYENTE; 4. EL DILEMA DE PARIS. UNA MIRADA A LA CLÁUSULA DE INTANGIBILIDAD A LA LUZ DE LA CONSTITUCIÓN ECONÓMICA; 5. CONCLUSIONES; BIBLIOGRAFía.

Yo quiero que la ley primera de nuestra República sea el culto de los cubanos a la dignidad plena del hombre.

JOSÉ MARTÍ

Crítica es el ejercicio del criterio. Destruye los ídolos falsos, pero conserva en todo su fulgor a los dioses verdaderos.

JOSÉ MARTÍ

\section{PROEMIO NECESARIO}

La Constitución de 1976 marcó un antes y un después en la historia de la nación cubana, no solo por sus postulados políticos sino porque fue el reflejo del cambio de contorno de la realidad de Cuba. Aunque la mayoría de la doctrina cubana coincide en que el texto constitucional es en realidad la validación jurídica de la defensa de un proyecto sociopolítico, tuvo ab ovo un poderoso componente económico. Por tanto, recorrer el controvertido camino de su creación, especificando cómo llegaron a plasmarse en ella los principales postulados de la regulación constitucional de la economía es una tarea per se inacabada, lo que convierte ipso facto a este trabajo en una aproximación provisional al tema en cuestión. Incluimos los procesos de reformas más trascendentales a los efectos del tema y la realidad existente con los cambios que se vienen implementando como parte de los Lineamientos de la política económica y social del partido y la revolución, muchos de los cuales carecen de amparo en la Constitución de 1976. Lo que configura la problemática esencial que trabajamos en esta obra.

Estos elementos configuran un escenario propicio en el empeño que asumimos de caracterizar el proceso de reformas económicas en Cuba desde los postulados constitucionales que fundamentan el sistema socioeconómico adoptado en la Carta Magna insular.

\section{CONSTRUYENDO UNA HISTORIA. CONSTITUCIÓN SOCIALISTA DE 1976}

El largo periodo de provisionalidad ${ }^{1}$ trajo la necesidad de dotar a la Revolución de un orden institucional. No fueron pocos los que se opusieron a "estatizar" el proceso de cambios que ya acumulaba casi dos décadas, sin embargo, el consen-

1 El periodo que versa entre 1959 y 1975 se conoce como de provisionalidad aludiendo precisamente a la forma de gobierno adoptada, declarada institucionalmente como provisoria. 
so en el país era más favorable en esa dirección. El proceso de elaboración de la Constitución fue también sui generis, el 23 de octubre de 1974 la Gaceta Oficial de la República daba a conocer la Comisión Redactora del magno texto insular encabezada por el viejo comunista Blas Roca CALDERio. Aunque la mayoría de los iuspublicistas ${ }^{2}$ marcan como punto de partida el nombramiento de la Comisión Mixta, lo cierto es que desde los primeros meses del año 1967 el Buró Político del recién constituido Partido Comunista de Cuba ya comenzaba a revisar en su seno las partes tentativas de una eventual Constitución.

Largo y complicado ha sido para estos autores sostener esta postura, contrario sensu de la mayor parte de la doctrina patria, pero queda claro en los manuscritos de Blas Roca ${ }^{3}$ que la primera versión de la parte dogmática del texto constitucional fue redactada para conocimiento del referido órgano el 14 de marzo de 1967. Este hecho hace naufragar las teorias que, hasta ahora, se esgrimian al respecto ubicando el origen del texto en la década de los setenta. Aunque, in honorem veritatem, Roca venía diseñando los artículos relativos a la propiedad en el magno texto desde $1966^{4}$.

Aunque mucho se ha pugnado acerca de la influencia soviética y del campo socialista en general en el texto constitucional cubano, aún persisten las posiciones enconadas desde los que la niegan furibundamente hasta los que la afirman de manera categórica. En este aspecto han resultado reveladores los primeros escritos de Blas RocA, a la sazón encargado por el Comité Central de los Asuntos Jurídicos, en los cuales se pueden encontrar las primeras posibles estructuras de la Constitución a partir de los estudios de la composición de las constituciones de Bulgaria y Rumania ${ }^{5}$. Por si quedara duda al respecto, en 1975 la Comisión Redactora elaboró un enjundioso documento en el cual se concordaba el anteproyecto de Constitución con sus homólogas del campo socialista, de las cuales se tomaron estilos de redacción e influyeron poderosamente en el cuerpo del articulado del texto definitivo. Resulta esclarecedor que, para la forma de este trabajo, se concordaba individualmente cada párrafo del preámbulo y cada uno de los artículos y el resultado final es de una similitud asombrosa ${ }^{6}$.

Aunque finalmente la Comisión Redactora optó por un modelo de Constitución Económica difusa, las primeras ideas que se propusieron y que revisó el Buró Político eran diametralmente opuestas. Se partía de la experiencia histórica de la Constitución de 1940 y se concentraban en un título las categorías de economía y propiedad. El destino final de esta idea quedó sellado el 13 de septiembre

2 Véase al respecto la obra de los doctores Martha Prieto Valdés, Carlos Villabella Armengol, Marta LoydaZaldivar Abad, Lissette Pérez Hernández.

3 Comité Central del Partido Comunista de Cuba, Departamento de Organización, Carta de Blas Roca al Buró Político remitiendo parte dogmática de la Constitución de 14 de marzo de 1967. Carpeta 122.

4 Comité Central del Partido Comunista de Cuba, Departamento de Organización, Notas personales de Blas Roca de fecha 18 de noviembre de 1966. Carpeta 91.

5 Ibid., folios 269 y 271.

6 Comité Central del Partido Comunista de Cuba, Departamento de Organización, Constitución Cubana Concordada con las Soviéticas, La Habana, 1975, carpeta 99, folio 144 
de 1966, cuando la Comisión de Estudios Constitucionales del referido órgano partidista observó que: "El relativo a la Economía y Propiedad [se refiere al título] lo pasaria a integrar el Capítulo Segundo a fin de vincular de manera directa los principios generales sobre el poder político a la base económica. Con este cambio se lograría además que los elementos social y humano quedaran unidos en lógica secuencia: Ciudadanía, Familia, Cultura, Derechos y Deberes Fundamentales y Propiedad"7.

El artículo 1 del texto aprobado ${ }^{8}$ define a la República de Cuba como un "Estado socialista de obreros y campesinos y demás trabajadores manuales e intelectuales". $\mathrm{El}$ artículo refleja de manera muy directa las concepciones ortodoxas marxistas muy vigentes, a la sazón, en la época. Sin embargo, encerró una interesante polémica al ser propuesto el nombre de República Socialista de Cuba por las organizaciones sociales y de masas que en plenos nacionales analizaron el anteproyecto. La Comisión Redactora siempre tuvo claro, como lo expresa la referida carta de Blas RocA al Buró Político, que era preferible conservar el nombre originario de la República nacida en Guáimaro, por representar lo más destacado de nuestras tradiciones de lucha y dejar el carácter socialista como calificativo del Estado nuevo que se estaba construyendo y que la Constitución legitimaría ${ }^{9}$. La clasificación de los obreros que se plantea respondió al carácter del trabajo de acuerdo con la filosofia marxista-leninista, y en ello hubo un general acuerdo entre las consideraciones de la CTC como las de otros consultados al efecto.

Nuestra Constitución es hija de un consenso social mayoritariamente permeado por la filosofia marxista-leninista ${ }^{10}$, por lo que es usual la utilización de categorias marxistas que tienen, en nuestro análisis, una gran importancia, toda vez que abierta y desembozadamente declaran una influencia sobre la base económica.

La revolución triunfante recibió el apoyo mayoritario de los campesinos en las montañas; al respecto argumentaba Blas RocA en un informe dirigido a la Comisión Redactora, donde significaba el papel importantísimo del campesinado en el triunfo y desarrollo del proceso revolucionario, sobre todo en las condiciones de nuestro país eminentemente agrario y subdesarrollado ${ }^{11}$. Así quedó confirmado en la redacción del artículo 4 apartado segundo al consignar la "firme alianza de los obreros con los campesinos".

7 Fernando Álvarez Tabío, “Observaciones de la Comisión de Estudios Constitucionales”, en Comité Central del Partido Comunista de Cuba, Departamento de Organización, carpeta 123, folio 44.

8 Comisión Redactora, Constitución de la República de Cuba, La Habana, Departamento de Orientación Revolucionaria del Comité Central del Partido Comunista de Cuba, 1976.

9 Estas consideraciones fueron resumidas en tres puntos esenciales que Álvarez Tabío resume en su obra. Véase Fernando Álvarez Tabío, Comentarios a la Constitución Socialista. La Habana, Ediciones Jurídicas, Editorial Ciencias Sociales, 1981, p. 29.

10 Aunque no son pocos los que argumentan que en realidad la influencia provenía del marxismo oficial soviético. Véase Fernando Martínez Heredia, En el horno de los noventa, La Habana, Editorial Ciencias Sociales, 2005, p. 174.

11 Comité Central del Partido Comunista de Cuba, Departamento de Organización, Nuevas Consideraciones sobre la proposición de hacer desaparecer la propiedad. Grupo 2 de la Comisión 3 de Estudios Jurídicos, carpeta 132, folios 1-46. 
En el artículo 8 se consagra un verdadero plan financiero orientado por la Comisión Redactora a los denominados poderes constituidos, al establecerse las actividades que el Estado socialista llevará a efecto para realizar la voluntad del pueblo trabajador y como poder del pueblo, en servicio del propio pueblo. En la primera de sus variantes se propone afianzar la ideologia y las normas de convivencia propias de un pueblo donde no existe la explotación del hombre por el hombre, lo cual es resultado directo, como dijimos anteriormente, de las vivencias de una época; además, se consagra la protección de la propiedad y las riquezas nacionales. Asimismo, se establece la dirección planificada de la economía. En la segunda, el Estado garantiza que no haya hombre o mujer en condiciones laborales, sin oportunidad de empleo que le permita contribuir a la sociedad y satisfacer sus necesidades; que no haya discapacitado sin atención; enfermo sin asistencia; niños sin escuela, alimentación y comida; joven sin oportunidad de estudiar; persona sin acceso al estudio, la cultura y el deporte; familia sin vivienda confortable.

En los elementos relativos al trabajo, resulta oportuno vincular estas expresiones con lo regulado en el artículo 44, donde se dice que el trabajo es un derecho, un deber y motivo de honor para los ciudadanos. Al respecto, es posible encontrar en nuestra sociedad disimiles criterios. Cuando nació la Ley 1231 de 16 de marzo de 1971, Ley contra la vagancia, no fueron pocos los oponentes que encontró en su camino $^{12}$. Lo cierto es que la Ley contra la vagancia fue un antecedente inmediato de la redacción de estas cuestiones en la Constitución. Fidel CASTRO, por entonces primer ministro del Gobierno Revolucionario, la consideraba "una gran batalla política y una gran victoria política"13. Asimismo, Blas RocA, aunque no miraba con buenos ojos "la vagancia y su forma oculta, el ausentismo", era del criterio que debería existir un artículo en la Ley de Enjuiciamiento Criminal regulándola bajo la forma de una medida de seguridad predelictiva ${ }^{14}$.

En esta misma línea, el segundo párrafo del artículo 44 planteaba las condiciones en las que se basaba la remuneración del trabajo, también este asunto provocó escozor y polémicas en la dirección revolucionaria y en la propia Comisión Redactora. JoRGE Risguet, ministro de Trabajo en la época, centraba su punto de vista en abrir "el abanico lo menos posible" en cuanto a las proporciones salariales ya que "la cuestión de la desproporción entre las remuneraciones mínimas y máximas, tiene una importancia de principio para el socialismo". En contraposición, Blas Roca planteaba que la preocupación sobre el abanico más cerrado o menos cerrado debía entenderse con respecto a la "cuantía de los sueldos de los funcionarios administrativos y de gobierno con la cuantía de los salarios de los trabajadores”.

12 Enemigos del proceso revolucionario vieron la oportunidad de rebajar el prestigio de Cuba frente al mundo. Véase, v. gr. OEA, Situación de los derechos humanos en Cuba. Séptimo Informe. Ser. L/V/ II.61. Doc. 29, rev. 14 octubre 1983, en http://www.cidh.org/countryrep/Cuba83sp/capitulo10. htm. Fecha de consulta: 11 de abril de 2012.

13 Fidel Castro Ruz, Discurso pronunciado por el Comandante Fidel Castro Ruz, Primer Secretario del Comité Central del PCC y Primer Ministro del Gobierno Revolucionario, en el Acto Central por el 1 de mayo de 1971, en http://www.cuba.cu/gobierno/discursos/1971/esp/f010571e.html. Fecha de consulta: 11 de abril de 2012

14 Comité Central del Partido Comunista de Cuba, Departamento de Organización, Borrador final de carta dirigida a Osvaldo Dorticós con sus consideraciones personales de Blas Roca sobre la Ley de la Vagancia, carpeta 137 . 
La polémica evidentemente tiene un sustento en las medidas leninistas del Partmaximun, que era una regla establecida después de la Revolución de Octubre que limitó el nivel de los salarios que podían recibir miembros del Partido Comunista que servian como funcionarios del Estado. Aunque funcionarios y obreros especialistas recibian un salario más alto que el de un obrero normal, los miembros del Partido Comunista no podían cobrar sueldos privilegiados sino que tenían que aceptar el sueldo de un obrero normal, esta regla fue abolida en 1930, en tiempos de la consolidación estalinista, y nunca se volvió a discutir su restauración ${ }^{15}$. Luego de esta polémica jamás se ha vuelto sobre el tema en el país, todas las discusiones salariales posteriores no cuestionan la filiación politica y versan con arreglo a las escalas establecidas.

El artículo catorce comienza a desarrollar las categorías de propiedad al establecer que en la República rige el sistema socialista de economía basada en la propiedad socialista de todo el pueblo sobre los medios de producción; a renglón seguido, el artículo 15 preceptúa que:

... la propiedad de todo el pueblo se establece irreversiblemente sobre las tierras que no pertenecen a los agricultores pequeños o a cooperativas integradas por los mismos; sobre el subsuelo, las minas, los recursos marítimos naturales y vivos dentro de la zona de su soberanía, los bosques, las aguas, las vías de comunicación; sobre los centrales azucareros, las fábricas, los medios fundamentales de transporte, y cuantas empresas, bancos, instalaciones y bienes han sido nacionalizados y expropiados a los imperialistas, latifundistas y burgueses, así como sobre las granjas del pueblo, fábricas e instalaciones económicas, sociales, culturales y deportivas construidas, fomentadas o adquiridas por el Estado. ${ }^{16}$

También, adentrándose en la categoría de bienes futuros, disponía la regencia de este tipo de propiedad sobre los bienes expectantes adquiridos o fomentados mediante los entes públicos.

Como señaló el propio RocA, citando a MARx, en notas con motivo del quinto aniversario de la proclamación de la Carta Magna cubana:

“...en la sociedad basada en los principios del colectivismo en la posesión común de los medios de producción nadie puede dar sino su trabajo, y por otra parte ahora nada puede pasar a ser propiedad del individuo fuera de los medios fundamentales del consumo. Esta concepción [la de MARx] es recogida por la vigente Constitución de 1976 en su artículo 15” ${ }^{17}$.

15 Allan Woods, Stalin. 50 años después de la muerte del tirano, en http://www.fundacionfedericoengels.org/index.php?option=com_content\&view=article\&id=112:stalin-50-anos-despues-de-lamuerte-del-tirano\&catid=43: cuaderno-de-formacion-marxista-no-7\&Itemid=63. Fecha de consulta: 11 de abril de 2012.

16 CubA. Constitución de la República. Ediciones de la Asamblea Nacional del Poder Popular. La Habana 2003

17 Comité Central del Partido Comunista de Cuba, Departamento de Organización, Notas sobre el quinto aniversario de la Constitución, carpeta 131. 
El articulado contenido entre el 16 y el 18 cumple la función de declarar la preeminencia de la planificación económica, consagrando la figura del Plan de Desarrollo Económico y Social, así como la facultad del ente estatal de crear "empresas y otras entidades económicas”. Esta comisión dedicó especial mención al referido plan, devenido instrumento constitucional para la dirección y el control de la actividad económica nacional. Si bien esta mención expresa resulta una innovación en el panorama del campo socialista, su objetivo es muy similar al "plan estatal de economía nacional" que el constituyente soviético consagró en el artículo 11 de la Carta Magna de la URSS ${ }^{18}$. En el proceso de discusión del anteproyecto por los militantes del Partido Comunista de Cuba existieron varias proposiciones, que finalmente no resultaron aprobadas, para incluir en este acápite la emulación socialista como medio de contribución a la economía nacional.

Asimismo, el artículo 18 constituye la exclusividad en la actividad estatal, siguiendo las concepciones leninistas en el comercio exterior, y el artículo 19 consagra un principio básico marxista fruto de la insistencia de la dirección de la Federación Estudiantil Universitaria ${ }^{19}$ : "En la República de Cuba rige el principio socialista ‘de cada uno según su capacidad; a cada cual según su trabajo”. Tal parecer se identificaba con el pensamiento de Blas RocA en la época: "quien más aporte a la sociedad con su trabajo regular debe recibir más de la sociedad, y ese más debe ser proporcional al más aportado".

Las otras formas de propiedad expresamente reconocidas en la redacción final se convirtieron en epicentro de una potente polémica. El mismo Blas RocA, en comunicación a Jesús MonTANé, ayudante en esos momentos del primer ministro, le informaba acerca de lo inquietante que resultaban algunos criterios de sus comisiones de estudio sobre una posible desaparición de todas las formas de propiedad del texto constitucional que se gestaba y argumentaba: "Si se propaga la noticia de que en las nuevas leyes que se preparan se elimina la propiedad personal podría originarse, similar a aquella sobre la patria potestad, de que esto significaba de que se les privaría de sus tierras, bueyes, etc." ${ }^{20}$.

Este debate había proliferado en la Universidad de La Habana en las Escuelas de Derecho y Filosofia, a ello se unía el clima creado por la dirección de la Revista Pensamiento Crítico. Este proceso, del que no teníamos anterior referencia, denota la complejidad teórica en que se debatieron los postulados esenciales de la ley fundamental criolla en materia de la regulación económica y contribuye a alejar las teorías antisépticas del fenómeno. Más adelante, en plena reunión con los inconformes, exponía: "esa bola que podía hacernos daño en particular respecto a

18 Comité Central del Partido Comunista de Cuba, Departamento de Organización, Constitución Cubana Concordada con las Soviéticas, op. cit., folio 208.

19 Comité Central del Partido Comunista de Cuba, Departamento de Organización, Actas de la Comisión Redactora de la Constitución de la República, 12 de julio de 1975, carpeta 90.

20 Comité Central del Partido Comunista de Cuba, Departamento de Organización, Comunicación a Montané, carpeta 91, folios del 385 al 391. 
las relaciones con el aliado fundamental de la Revolución en el periodo de la construcción del socialismo y el comunismo, es decir, con el campesinado" ${ }^{21}$. Esta lógica de razonamiento es también adoptada rápidamente por el Buró Político y en documento preparado para contrarrestar esta opinión se reflexionaba:

“... la fase del proceso en que nos encontramos, aparte de la propiedad campesina, es la propiedad personal que existe en nuestro país sobre una serie de bienes tales como la máquina de coser, el radio o el televisor, el automóvil, la ropa que se usa, y aún de instrumentos de trabajo como, para poner un solo ejemplo el de los camiones de propiedad particular, muchos de los cuales han tomado parte activa, manejados por sus dueños en la gran zafra que ya se ha ido por delante en más de l’000.000 de toneladas de azúcar de la mayor de la que fue capaz de hacer el capitalismo en Cuba"22.

Finalmente, quedaron reconocidas la propiedad de los agricultores pequeños, la propiedad cooperativa y la personal. En relación con la primera, un grupo de campesinos planteaba que era necesario incluir que el Estado fuese el único comprador de tierras agrícolas, y otro grupo, separata modum, planteaba que no era necesario que el ente público se reservara tal facultad. Por último, la fórmula adoptada fue configurada a partir de un derecho de adquisición preferente al plantear que: "En todo caso, el Estado tiene derecho preferente a la adquisición mediante pago de su justo precio". La configuración final de este tipo de propiedad en el magno texto obvió proposiciones mucho más radicales que clamaban por reconocer "el disfrute de la tierra a los agricultores pequeños a título de usufructuarios" o "fijar la extensión de la tierra de que podrán disfrutar los agricultores pequeños" 23 . La propiedad cooperativa disfrutó de amplio consenso, aunque se observaba por los trabajadores la necesidad de "otros tipos de cooperativas privadas" ${ }^{24}$, el texto concluido solamente las circunscribió al aspecto agrícola.

En carta dirigida a Blas Roca el 17 de febrero de 1975 el presidente Osvaldo DoRTICós reflexionaba:

"En el anteproyecto de Constitución se menciona la propiedad estatal socialista y las propiedades de los agricultores pequeños, cooperativas, así como la propiedad personal que regula el artículo 17. En cambio, no se hace mención en todo el texto a un tipo de propiedad que existe en la economía socialista, me refiero a las propiedades de las organizaciones sociales, por ejemplo, de los sindicatos y a las del partido. Se trata de dos situaciones en que no nos encontramos ante una propiedad estatal ni tampoco privada o personal. Creo que debe existir un precepto referido a este tipo

21 Idem.

22 Véanse al respecto las Nuevas Consideraciones sobre la proposición de hacer desaparecer la propiedad, Grupo 2 de la Comisión 3 de Estudios Jurídicos, supra cit.

23 Comité Central del Partido Comunista de Cuba, Departamento de Organización, Proposiciones de Modificaciones del Texto del Anteproyecto de Constitución agrupadas por razón de similitud, carpeta 89, folios 1 al 130 .

24 Idem. 
de propiedad. [...] La Constitución de la RDA en su artículo 10 la menciona [...] la búlgara la incluye en su artículo $14{ }^{\prime 25}$.

A partir de este correcto razonamiento se incluyó la figura de la propiedad de las organizaciones sociales y de masas al anteproyecto que se votó por la ciudadanía y continúa vigente hasta hoy. En este tema es de señalar una cuestión importante, con posterioridad a la redacción del texto constitucional nunca se dictó ley o norma reglamentaria alguna para enrumbar en el tráfico jurídico la referida propiedad. El asunto se vuelve más complejo aún si tomamos en cuenta que la mayoría de las organizaciones sociales y de masas en nuestro país, desde la época, trabajan sus propiedades, en la práctica, como patrimonio estatal. Esta realidad desdibuja en cierta medida los postulados clásicos gramscianos de la sociedad civil pero, al objeto de nuestro trabajo, es sumamente trascendente porque forma parte de la propia base económica del sistema.

Algo revelador resulta la moderna Ley de la Contraloría General de la República ${ }^{26}$ pues allí, en el artículo 12, apartado segundo, inciso c), se declara la posibilidad de que el aparato gubernamental de control audite con el objeto de fiscalizar el empleo de los fondos públicos a las organizaciones políticas de masas y sociales. El 12.3 complementa esta visión al disponer que se actúe previa solicitud de las máximas autoridades de las mismas y luego arroja un poco más de duda cuando en forma disyuntiva añade "o a instancia del Consejo de Estado". Aquí el problema constitucional tiene dos perspectivas evidentes, una que al no dictarse normas complementarias que distingan claramente la figura de las organizaciones sociales y de masas la tradición ha jugado el papel de elemento distintivo pues se consideran como tales aquellas que fueron taxativamente nombradas en la redacción del texto antes de la reforma de 1992, pero nada obsta a otras a considerarse como tales dada la inexistencia de normas de reconocimiento. En ese sentido, la ley supra citada confunde, más que aclarar, la cuestión; la verificación de fondos públicos arroja un problema más bien teórico en el asunto del soporte económico, sin embargo, es un reconocimiento tácito de la preeminencia de la propiedad estatal sobre la forma que analizamos, confirmando su contenido vacuo.

Otra no menos grave es el limbo jurídico en que se encuentran las propiedades de las asociaciones, constituidas bajo el manto de la Ley homónima, que en su artículo segundo, último párrafo, establece como requisito sine qua non para su reconocimiento no estar comprendida en la mención del constituyente en el artículo referido a las organizaciones sociales y de masas ${ }^{27}$. Respecto a las propiedades de estas personas jurídicas la ley es omisa, lo que arroja no pocas in-

25 Osvaldo Dorticós Torrado, “Carta a Blas Roca de fecha 17 de febrero de 1975”, en Comité Central Del Partido Comunista de Cuba, Departamento de Organización, carpeta 110, folios 1 al 17.

26 Cuba, Asamblea Nacional del Poder Popular, "Ley No. 107 de la Contraloría General de la República de Cuba”, en Gaceta Oficial de la República de Cuba, No. 029 de 14 de agosto de 2009. Extraordinaria, Año CVII, p. 168.

27 Cuba, Asamblea Nacional del Poder Popular, Ley No. 54 Ley de Asociaciones, en http://www.parlamentocubano.cu/index.php?option=com_content\&view=article\&id=268:ley-no-54-ley-de-asociaciones\& catid=46:leyes\&Itemid=79. Fecha de consulta: 11 de abril de 2012 
terrogantes. Como insistiamos supra, en la práctica contable, financiera y hasta politica, las propiedades reciben un tratamiento tan similar a la estatal que, a veces, resulta indistinguible.

En relación con la herencia, en sentido general, no hubo mayores contratiempos, sin embargo, el parágrafo segundo fue el resultado de pasiones geográficas exaltadas pues el Oriente y el Occidente planteaban elementos totalmente contrapuestos. Por un lado, se concebían como herederos con vocación "a los hijos vinculados al trabajo agrícola y a los obreros que vivan en la finca”, y por otro, "a todos los hijos y no solamente a los que trabajan la tierra". Igualmente, se proponía tener en cuenta a "esposas e hijos cuyo ingreso fundamental es por la producción de la finca y que no trabajan la tierra", así como a "aquellos hijos de campesinos que son llamados al SMG, EJT, u otras instituciones que de acuerdo a las necesidades del Estado tengan que permanecer tres o más años fuera de la finca. Que se les considere como herederos de la misma ya que su salida se ha originado por necesidad ajena a su voluntad".

La expropiación de bienes fue una figura jurídica que contó con la aquiescencia general, el propio Buró Político reconoció en un análisis de las propuestas de modificaciones que "solo reflejan confusiones en cuanto a lo que es la expropiación y lo que es la confiscación que se aplica como sanción”; más adelante orientaba: "proponemos que se mantenga la redacción propuesta de los artículos 23, 24 y 25" 28 . En relación con los derechos socioeconómicos el propio RocA, desde la fase primigenia del proceso, señalaba: "Creemos que los derechos sociales que deben consignarse en la Constitución son aquellos que ya están garantizados con medidas materiales que hacen posible su real satisfacción" ${ }^{29}$. Más adelante reflexionaba: "La Constitución Socialista en el terreno económico, social y cultural no proclama derechos jurídicos o legales que se quedan en el papel: proclama derechos reales, efectivos, vigentes en la sociedad. Tampoco inventa derechos deducidos de los ideales del igualitarismo pequeñoburgués sino que parte de las diferencias reales que todavia subsisten" ${ }^{30}$. El viejo comunista sopesaba en notas de 1965 los principales derechos que se debían desarrollar, como el derecho al trabajo, a recibir una parte del producto social acorde con el trabajo realizado, el derecho al descanso y a la instrucción.

Tandem, se reflejaron los principales derechos, ora desde una perspectiva estatocéntrica, haciendo honor a la corriente imperante en la época, ora desde los derechos de segunda generación. Así, en el artículo 38 quedó expresada la responsabilidad estatal para con la educación. Las proposiciones de modificación a este tema fueron hipervariadas, correspondiendo más a reglamentos administrativos, al menos a las que estos autores tuvieron acceso, que a preceptos constituciona-

28 Buró Político, Consideraciones en torno a las modificaciones propuestas al Anteproyecto de Constitución, en Comité Central del Partido Comunista de Cuba, Departamento de Organización, carpeta 92, folio 17.

29 Comité Central del Partido Comunista de Cuba, Departamento de Organización, Notas, carpeta 124, folios 212-226.

30 Ibid., folios 383 al 385. 
les. Tal fue la opinión del máximo órgano ejecutivo del Partido Comunista que al analizarlas señalaba:

\begin{abstract}
"Son muchas las modificaciones propuestas al artículo 38. Las proposiciones van desde definir en la constitución la obligatoriedad de la enseñanza de ciertas materias hasta prescribir que sea sancionado quien trate de convencer a un becado que abandone los estudios. Se ha propuesto también que en el texto constitucional se consigne la edad hasta la cual es obligatoria la enseñanza y que el joven que comience una carrera debe terminarla y ejercerla o, en caso contrario, reintegrar al Estado los recursos empleados en su formación, así como que el Estado controlará la moda para que se sepa a simple vista de qué sexo es el que la usa”.
\end{abstract}

Más adelante, en tono más reflexivo, apuntaba: "La Comisión Redactora ha recomendado no acoger estas y otras muchas de las proposiciones hechas"31. La redacción final quedó sin muchas variaciones.

Las tendencias que signaron el artículo anterior se hacen extensivas a los principales servicios prestados por el Estado, consignados como derechos socioeconómicos. En lo relativo a las funciones estatales se establecieron las relativas a la economía, concentradas entre el máximo órgano de gobierno y la Asamblea Nacional.

La Constitución de 1976 marcó un importante hito en la regulación de las nuevas realidades sociales; en relación con la Constitución Económica se definió un modelo socialista, y en su referencia en el texto se decidió hacerlo de manera difusa, por las razones supra citadas; sin embargo, al ser sus normas esencialmente programáticas, dejaba a la ley un rol esencialísimo en el desarrollo de sus postulados, lo que en el futuro incidiría en su capacidad de reconocer las principales relaciones sociales.

\title{
2. UNA REFORMA NECESARIA. LA CONSTITUCIÓN ANTE LOS EMBATES DEL PERIODO ESPECIAL
}

La caída del campo socialista marcó un periodo de crisis para la historia de Cuba. Apenas un par de años antes, en 1989, durante el acto por el Día de la Rebeldía Nacional celebrado en Camagüey, FIDEL alertó sobre la posibilidad, imperceptible para muchos aunque realidad palpable para otros, de que colapsara el sistema socialista mundial. Aquella exposición se haría realidad dos años más tarde. Cuba se vio ante una encrucijada, la profunda crisis que pronto se entronizaría en nuestra sociedad haría al Gobierno tomar medidas que permitieran paliar la situación, radicales y concretas, novedosas y contradictorias con muchos conceptos manejados hasta entonces, aristas que veremos a continuación.

31 Comité Central del Partido Comunista de Cuba, Buró Político. Consideraciones en torno a las modificaciones propuestas al Anteproyecto de Constitución, cit., folios 19 y 20. 
En 1991 tuvo lugar, en la provincia de Santiago de Cuba, el IV Congreso del Partido, en cuyo seno se analizó la cuestión de una eventual modificación de nuestra Constitución. El llamamiento a esta importante reunión partidista ha sido, por mucho, el más crítico que se ha realizado en la historia de estas citas, alli se consagraban importantes elementos que condicionaban el clima político en que se efectuaría la Reforma ${ }^{32}$, y se expresaba la voluntad de que:

“...debemos avanzar en la elaboración del modelo de desarrollo económico y social para los próximos años. [...] Reafirmaremos, en consecuencia, la vigencia de nuestro programa socialista, que es el que permite al pueblo cubano [...] tener garantizado el derecho al trabajo, altos niveles de educación, salud, seguridad social, alimentación básica y una vida digna y decorosa"33.

Con lo anterior se pautaba apriorísticamente el alcance de las modificaciones constitucionales.

Otro elemento, olvidado en muchas ocasiones, es el papel de la ideología en la economía, definido por el cónclave, señalando: "La rectificación [se refiere al proceso de Rectificación de Errores y Tendencias Negativas] nos condujo a reasumir el papel protagónico de la ideología revolucionaria, relegado por el falso criterio de la eficiencia espontánea de los mecanismos económicos”. Entre el 10 y el 12 de julio de 1992, se dieron cita en la ciudad de La Habana los diputados a la Asamblea Nacional del Poder Popular para discutir y aprobar los cambios que se proponían al texto cubano, como resultado del largo proceso de investigaciones y estudios desarrollados por especialistas del Partido y el Estado, iniciados antes de que comenzaran las labores organizativas del Congreso partidista ${ }^{34}$.

La presidencia de la asamblea correspondió al compañero Juan EsCALONA REGUERA, quien presentó ante los asistentes el informe inicial sobre las propuestas y explicó los antecedentes de dichos cambios, así como la situación del país en el momento en que se proponian. Consideraba que la revolución había salido fortalecida del proceso "rectificador" realizado la década anterior; manifestaba por entonces: "La decisión de perfeccionar nuestra sociedad adquirió una fuerza adicional en el llamamiento a la rectificación de errores y tendencias negativas que formulara nuestro Comandante en Jefe en abril de 1986, el que permitió devolver a nuestro proceso la originalidad y fuerza creativa que habian constituido desde su inicio, los más valiosos rasgos de la Revolución cubana”35.

32 Nos llamó la atención, a guisa de curiosidad, que el propio encabezamiento del documento alude a la clasificación primigenia de los trabajadores manuales e intelectuales contenida en el artículo primero de la Constitución pre reformada tal y como sigue: "a sus militantes, a la clase obrera, a los campesinos, a todos los trabajadores manuales e intelectuales", sin embargo, en la reforma se eliminó del texto constitucional la referida mención.

33 Partido Comunista de Cuba, "Comité Central, ¡Al IV Congreso del Partido! ¡El futuro de nuestra Patria será un Eterno Baraguá!”, Periódico Granma, 18 de marzo de 1990.

34 Cuba, Asamblea Nacional del Poder Popular, Tercera Legislatura, Actas Décimo Primer Periodo Ordinario de Sesiones, 10 de julio de 1992, p. 5.

35 Idem., p. 6 
Dentro de las modificaciones propuestas a la Asamblea se enumeran una serie de cambios en conceptos económicos ${ }^{36}$ :

Artículo 14. En él se precisa que la propiedad socialista está referida a los medios de producción fundamentales.

Artículo 15. Se relacionan los bienes que constituyen propiedad estatal socialista, proponiéndose que desaparezca el carácter de irreversibilidad que ostenta hasta ese momento, además de autorizar la trasmisión de dicha propiedad con el límite de que se destine a los fines del desarrollo económico y social del Estado previa aprobación del Consejo de Ministros o de su Comité Ejecutivo.

Artículo 16. Se propone la desaparición del "rígido Plan Único de Desarrollo Económico Social”, proponiéndose la organización, dirección y control de la actividad económica "conforme a un plan que garantice el desarrollo programado del país" con la participación activa de los trabajadores en la elaboración y ejecución de los "programas de producción y desarrollo".

Artículo 17. Se establecen dos variantes para la administración de los bienes de propiedad socialista: una, directamente organizada por el Estado; otra, organizada por empresas y entidades encargadas de realizarla.

Artículo 18. Se propone la sustitución de la formulación de que el comercio exterior es de función exclusiva del Estado por otra más flexible, siguiendo el sentido de que el "Estado dirige y controla el comercio exterior"; además, se reserva a la ley la potestad de establecer las instituciones o autoridades facultadas para crear empresas de exportación e importación, así como determinar las personas jurídicas con capacidad para realizarlas.

Artículo 23. Reconoce la propiedad de las empresas mixtas, sociedades económicas y asociaciones que, además de la ley, se rigen por sus propios reglamentos, estatutos y tratados con respecto al uso y disfrute de sus bienes.

Antes de realizar nuestro análisis debemos señalar dos elementos importantes. Uno de ellos parte de las propuestas realizadas a los diputados con conceptos que hasta entonces hubieran parecido una locura, pero que la dirección del país veía en ellos la única salida probable; estas cuestiones económicas que propone son las que considera más relevantes y oportunas. El otro aspecto está relacionado directamente con el debate que estas medidas originaron entre los asistentes y las nuevas propuestas que salieron de su seno y no estaban previstas, también eran de suma importancia a los efectos del tema que tratamos.

La propiedad estatal socialista trajo varios acordes al debate en cuestiones económicas. Así, lidiábamos entre mantener la propiedad del Estado sobre todos los

36 Ibid., pp. 7-8.

DÍKAION - ISSN 0120-8942 
medios de producción - como aparecía el artículo 14 originalmente redactadoo sobre los "medios fundamentales de producción" - propuesta presentada a los diputados-. Ello, visto a la luz de la propuesta de cambios al artículo 15, desató cuestionamientos profundos sobre el destino del socialismo en Cuba.

A partir de las valoraciones sobre el artículo 14 se presentaron evidentes dudas sobre la amplitud del término "fundamentales", siendo criterio que se especificara a qué "medios fundamentales de producción" se estaban refiriendo. JuAn Escalona argumentaba el vínculo de este artículo con el 15, en el cual se determinaban taxativamente los bienes que formaban parte de esa clasificación en los incisos a) y b), cuya amplitud en la redacción va destinada a que se abra el espectro hacia la mayor cantidad de cosas posibles, incorporando una serie de bienes que el Estado puede adquirir en el futuro y la Constitución necesita salvaguardar el derecho que sobre estos pueda tener.

Por otro lado, en otro párrafo del mismo artículo se elimina la irreversibilidad de la propiedad estatal socialista, característica que no permitía en modo alguno su transmisión, resultando una incómoda camisa de fuerza. La nueva redacción, más flexible, establecía la regla de no transmisión de estos bienes a personas naturales o jurídicas, incorporándole a modo de excepción, lo siguiente: “...salvo los casos excepcionales en que la trasmisión parcial o total de algún objetivo económico se destine a los fines del desarrollo del país y no afecten los fundamentos políticos, sociales y económicos del Estado, previa aprobación del Consejo de Ministros o su Comité Ejecutivo".

La presidencia ofreció a los diputados una explicación que fundamentaba la imposibilidad de traspaso como regla y su excepción: “... no hay traspaso posible. Entonces, tenemos que dejar abierta alguna puerta para que situaciones coyunturales muy precisas nos obliguen a decir "salvo" que nosotros tengamos la necesidad de hacerlo". De ahí que se reserve a la más alta dirección del Gobierno la decisión sobre este particular. Más adelante se decía: "Si nosotros dijéramos que esto se puede traspasar estariamos dándole una puñalada al socialismo; y por ahí se nos podía escapar el socialismo" 37 .

Evidentemente, el país no tenía más remedio que admitir el traspaso de la propiedad estatal socialista ante determinadas circunstancias. Necesitábamos atraer inversionistas a Cuba con garantias de que se les respetarian sus propiedades; además, los necesitábamos para poder desarrollar ciertos sectores en los que no teníamos ninguna experiencia debido al aislamiento en que habiamos estado durante mucho tiempo ${ }^{38}$. FIDEL fue categórico al remitirse a las decisiones que se estaban ventilando y lo que representaban para el futuro de la nación: "Estas modificaciones que se proponen tienden a adecuar nuestra ley a situaciones que la vida nos ha impuesto, a realidades que la vida nos ha impuesto ¿Es un retroceso? Sí,

37 Ibid., pp. 126-128.

38 Palabras del presidente de los Consejos de Estado y de Ministros a los diputados a la Asamblea Nacional del Poder Popular. Ibid., p. 132. 
es un retroceso [...] hay cierto momento, incluso, en que una revolución tiene que hacer concesiones, tiene que hacer retrocesos" ${ }^{39}$. Ello era una necesidad historica. Precisamente por lo que representan esos cambios estos autores se permiten disentir en la variante propuesta con respecto al órgano encargado de tomar la decisión sobre los traspasos de la propiedad estatal socialista. Si bien es cierto que los órganos encargados de la administración del Estado deben estar al tanto de la politica de sus respectivas esferas y, por ello, deben conocer directamente sobre las necesidades reales de sus sectores, consideramos que tal decisión debería estar limitada. En Cuba especialmente, donde persiste un sistema socioeconómico tan particular, la propiedad estatal socialista sobre los medios fundamentales de producción constituye una de sus mayores fortalezas y uno de los fundamentos de dicho sistema; de hecho, constituye una cuestión de principios del propio sistema.

Debido a lo anterior, consideramos que a un órgano que solo se encarga de cuestiones administrativas, decidir sobre algo que implicaría un reflejo inmediato en el sistema socioeconómico reconocido por la Constitución -aunque ella misma lo ponga como excepción - podría traer efectos negativos para el Estado y el pueblo cubanos. Por tanto, consideramos necesario que se pongan limites al actuar del Consejo de Ministros y su Comité Ejecutivo en esta clase de decisiones, las cuales pueden ser en relación con la cuantía sobre la que pueden decidir y con los tipos de bienes sobre los cuales se toma la decisión. La decisión que se tomaría al superar ese limite correspondería a la Asamblea Nacional del Poder Popular por constituir nuestro órgano supremo y representar y expresar la voluntad soberana de todo el pueblo. Al tratarse de los servicios fundamentales de la población, se requería un referéndum, determinando la propia Asamblea cuáles serían esos servicios fundamentales ${ }^{40}$.

Estos elementos son tan solo algunas directrices que una futura Constitución podría saldar dejando establecidas ciertas pautas al poder constituido.

Uno de los temas que no se había propuesto y salió a colación fue el de las cooperativas de producción agropecuaria, las únicas reconocidas en la Constitución. El diputado Fidel CASTRO era categórico al respecto y consideraba que la Constitución no podía reconocer gran variedad de formas cooperativas porque representaban un atentado al sistema socialista. Decía:

\begin{abstract}
"Ahora, nadie ha pensado en una cosa, Juanito [Escalona Reguera], que toda la perestroika empezó hablando de cooperativas, de cooperativas de servicios, de cooperativas de tiendas, cooperativas de negocios y todo camino del capitalismo a toda velocidad. No debemos olvidarnos de esos otros pequeños riesgos que parezca exaltada demasiado la propiedad cooperativa.
\end{abstract}

Creo que debiéramos distinguir un poco y decir 'de propiedad cooperativa agrícola' para distinguirla frente a cualquier tendencia de querer generalizar el concepto de

39 Ibid., p. 130.

40 En el criterio de estos autores debería tenerse en cuenta como contenido mínimo de esos servicios fundamentales la salud, educación y cultura, deporte y alimentación. 
cooperativa; porque si funciona la agricultura debemos decir 'forma de propiedad cooperativa agrícola'. En ese sentido, con esta preocupación, más que volver a decir 'constituye una forma de propiedad cooperativa', pudiera ser una forma avanzada y eficiente de producción socialista, esta, la cooperativa agrícola, la que se refiere al campo".

Más adelante agregaba: “...lo que pasa es que, a mi juicio las cooperativas funcionan muy bien en el campo, y son agricultores que eran dueños de la tierra. Lo que quisieron hacer allá fue convertir propiedades del Estado en propiedades cooperativas, repartir propiedades del Estado en propiedades cooperativas" ${ }^{41}$.

Con estos criterios se dio por sentado el tema de las cooperativas, pero el asunto de las empresas mixtas recién daba los primeros pasos. La Asamblea reflexionó sobre la creación de empresas con capital extranjero en cualquiera de sus variantes, ya sea parcial o total. Esta propuesta traía el mismo fundamento de otras que se trajeron a análisis. Para que veamos tan solo alguna arista de la cuestión basta con señalar que, en esos primeros años que le siguieron a la caída del campo socialista, Cuba estaba viviendo con el $40 \%$ de las importaciones que recibía con anterioridad; con la venta de una tonelada de azúcar se podian comprar 1,4 toneladas de petróleo ${ }^{42}$.

Las empresas mixtas constituían una de las vías encontradas para aumentar el índice de inversión extranjera directa y con ello garantizar nuestra inserción en el mercado internacional. En Cuba, según el diputado Fidel CASTRo, no existía personal capacitado para administrar, por ejemplo, hoteles; no así los centrales azucareros con los que llevábamos años de experiencia. Lo que se pedía a todos era el respeto y la seriedad en estas incursiones novedosas para evitar problemas con los inversionistas extranjeros.

Sobre las formas colectivas de propiedad, Carlos Rafael RoDRíGuEz planteaba, con certeza, que debíamos ser cuidadosos, pues no siempre implicaban que eran socialistas o que estaban inclinadas al socialismo ${ }^{43}$. Es más, gran parte de las sociedades mercantiles existentes compiten en el mundo por el dominio del mercado, en el capitalismo han sobrevivido y mueren a diario ${ }^{44}$; ese resultaba un mundo nuevo para nosotros.

Por otro lado, la eliminación del Plan Único de Desarrollo Económico Social intenta establecer una politica más flexible que permita mayor agilidad y participación popular. Con esto se intentan eliminar ciertas trabas burocráticas que entorpecen el correcto funcionamiento de nuestro sistema económico. Así se lega al poder cons-

41 Criterio del diputado Fidel CASTRO ofrecido a los diputados a la Asamblea Nacional del Poder Popular. $\mathrm{Al}$ respecto véanse las Actas supra citadas.

42 Ibid., p. 132.

43 Idem.

44 Véase Susan George, Otro mundo es posible si..., La Habana, Editorial Ciencias Sociales, 2002. 
tituido cierta discrecionalidad en su actuar, lo que le permitirá adoptar planes con el menor o mayor alcance posible dependiendo de las necesidades del momento. Nuestra Constitución Económica no perdió su carácter difuso y mantuvo algunos rezagos del pasado, aunque no podemos negar su carácter práctico, correcto o no, pero necesario. La Constitución, además de representar un giro radical en las políticas económicas - entre otras - del país, significó un punto de partida por la supervivencia de la nación y su sistema socioeconómico ${ }^{45}$.

\section{LA CONSTITUCIÓN ECONÓMICA DE 1976. ENTRE LA REFORMA Y LA CONSTITUYENTE}

El 8 de noviembre de 1993 el Consejo de Estado dicta el Decreto-Ley 141 derogando lo establecido en el Decreto-Ley 14 de 3 de julio de 1978 y otorgándole un nuevo marco jurídico a la institución del trabajo por cuenta propia. No son objeto de este trabajo las diversas ramificaciones teóricas y exegéticas de la categoría, sin embargo, para estudiar el marco institucional que la reforma de 1992 legó resulta imprescindible repasar algunos elementos prístinos del desarrollo de esta institución.

Hay que añadir, en este sentido, que su regulación no resulta una novedad pues la joven revolución la reconoció mediante la Ley 1213 de 27 de junio de 1967; a los efectos del hilo histórico que exponemos, resulta importante la justificación que en el exordio del Decreto-Ley 14 se consigna, al plantear: "El desarrollo y organización de la economía nacional no asegura aún que las empresas y unidades presupuestadas estatales puedan satisfacer de manera integra las necesidades de determinados productos, principalmente artesanales, o algunos servicios indispensables para la población y también para las entidades estatales mismas" ${ }^{46}$. Estas razones sustentaban la ampliación de la esfera de acción de esta categoría; sin embargo, planteaban un dilema constitucional. El magno texto establecía en su artículo 14 la prohibición de la explotación del hombre por el hombre, lógica razón si se tiene en cuenta que este axioma constituye la esencia de la pequeña producción mercantil privada, simiente material del capitalismo premonopolista. Por ello, el Decreto-Ley 14, en su formulación original, artículo primero, suprimía la posibilidad de contratar mano de obra asalariada. La formulación de la norma que le precedió en vigencia, sin dudas, es un poco más laxa, aunque mantuvo como limite la explotación excesiva de fuerza de trabajo, al establecerse como conductas susceptibles de contravenciones "la contratación de los servicios de trabajadores sin estar autorizado o en actividades en que no está establecida su utilización, de acuerdo con lo dispuesto en la legislación vigente" ${ }^{7}$. Si bien, estricto sensu,

45 Para mayor información sobre el tratamiento dado a la propiedad por la Constitución Cubana de 1976. Véase Josefina Méndez López y Danelia Cutié Mustelier, "La propiedad en Cuba. Una visión desde la Constitución”, en AA.VV. Panorama de la Ciencia del Derecho en Cuba. Estudios en homenaje al profesor Dr. C. Julio Fernández Bulté, Facultad de Derecho de la Universidad de La Habana - Ed. Lleonard Muntaner, 2009, pp. 343-360.

46 Cuba, Consejo de Estado. Decreto Ley 14 Sobre el ejercicio de actividades laborales por cuenta propia, de 3 de julio de 1978, Archivo Digital de la Biblioteca de la Asamblea Nacional del Poder Popular.

47 Cuba. Consejo de Estado, Decreto Ley 274 de 30 de septiembre de 2010 Modificativo del Decreto-Ley No. 174/97, "De las contravenciones personales de las regulaciones del trabajo por cuenta propia",

DÍKAION - ISSN 0120-8942 
era un contrasentido con lo dispuesto en el párrafo primero del artículo 14 de la Constitución, la limitación establecida vendría a constituir un importante signo de respeto teleológico al mandato del constituyente, dada la complejidad de las circunstancias en el momento en que se dicta la norma. Nadie, en su sano juicio, podría justificar que no existiese explotación del hombre por el hombre, pero el hecho de limitar el número a determinadas actividades económicas y privilegiar las que utilizasen fuerza de trabajo familiar es un claro intento de poner coto a las circunstancias que la categoría jurídica planteaba.

El Sexto Congreso del Partido es celebrado en uno de los momentos más álgidos en la historia de la nación. La Constitución Económica se torna un tema polémico y absolutamente necesario en el seno de nuestra sociedad. Si se tuviera duda remitámonos a las palabras de clausura del IX Congreso de la Unión de Jóvenes Comunistas, cuando a manera de sentencia, el general de Ejército Raúl CASTRo, presidente de los Consejos de Estado y de Ministros, expresó: "La batalla económica constituye hoy, más que nunca, la tarea principal y el centro de trabajo ideológico de los cuadros, porque de ella depende la sostenibilidad y preservación de nuestro sistema social" 48 . Los retos de la nación y la sociedad, como ente más englobador, son enormes, o funciona el experimento o perece el proyecto nacional. Los lineamientos, ampliamente discutidos por la población cubana ${ }^{49}$, delinean lo que se ha denominado actualización del modelo de gestión económica. Esto ha traído no pocos quebraderos de cabeza pues muchos de estos postulados colisionan con preceptos constitucionales y una parte importante de la doctrina jurídica patria argumenta que se trata de una reforma profunda a las bases del sistema ${ }^{50}$. Por otro lado, existe otra posición que esboza la imposibilidad de una reforma constitucional que refleje esta política económica dado el impedimento que plantea la cláusula pétrea añadida en 2002 por la Asamblea Nacional del Poder Popular al artículo tercero de la Constitución instituyendo la intangibilidad del sistema político y social establecido por el magno texto, con lo que la explotación del hombre por el hombre sería inconcebible en el marco del socialismo ${ }^{51}$, sea cual fuere la forma de su implementación. Por lo que, en este caso, sería requisito sine qua non la promulgación de una nueva Constitución.

Archivo Digital de la Biblioteca de la Asamblea Nacional del Poder Popular.

48 VI Congreso del Partido Comunista de Cuba, Lineamientos de la politica económica y social del Partido y la Revolución, 18 de abril de 2011, p. 1.

49 La discusión se realizó en tres etapas: discusión del documento por todo el pueblo entre diciembre de 2010 a febrero de 2011; discusión en cada provincia por los delegados e invitados al Congreso, 8 al 10 de abril de 2011; por las Comisiones durante el Congreso 17 y 18 de abril de 2011. De los lineamientos originales (291) se mantuvieron el 32\% siendo modificados 197 de ellos (181 modificados y 16 integrados con otros) e incorporados resultaron 36. En la segunda etapa se aprobaron presentar al Congreso 257 propuestas sobre 146 lineamientos. En el tercer periodo se modificaron 86 lineamientos y se incorporaron 2.

$50 \mathrm{Al}$ respecto se han pronunciado los doctores Lissette Pérez Hernández, Andry Matilla Correa y Martha PRIETO VALdÉs; entrevistas personales concedidas especialmente para este texto.

51 Los doctores Martha Prieto Valdés, José Walter Mondelo García, René Fidel González García, Julio FERnÁNDEZ Estrada y Julio CÉSAR GuANCHE; entrevistas especiales para este trabajo, obras de los autores y conferencias ofrecidas en diversos eventos. 
El capítulo primero de los Lineamientos de la politica económica y social del partido y la revolución se dedica exclusivamente al modelo de gestión económica. El artículo primero consagra la intención de que la planificación continúe siendo la vía principal para la conducción de la economía nacional en consonancia con el artículo 16 de la Constitución al afirmar este último que: "El Estado dirige y controla la actividad económica nacional conforme a un plan que garantice el desarrollo programado del país”. Ahora bien, también se consigna en el referido documento la posibilidad de creación de cooperativas fuera del sector agropecuario ${ }^{52}$, lo que colisiona frontalmente con el mandato constitucional; asimismo, reconoce la figura de las cooperativas de segundo grado, formadas por las proyectadas como primarias, con el objeto de "organizar actividades complementarias afines o que agreguen valor a los productos y servicios a sus socios, o realizar compras y ventas conjuntas con vistas a lograr mayor eficiencia"53.

La Constitución, por su parte, garantiza únicamente las "cooperativas de producción agropecuaria” en su artículo 20, en los párrafos del segundo al cuarto. No es el objeto de nuestro trabajo plantear la teoría de esta forma de propiedad social; no obstante, es necesario acotar que la extensión de esta institución en los términos que plantea el documento partidista supone importantes riesgos para el sistema defendido bajo la Constitución, pues aunque se declara que se tratará de evitar la concentración de la propiedad, ello no es garantía suficiente de la preservación del sistema. Nótese que las cooperativas de segundo grado propugnan mayor volumen de comercialización, compras, ventas y, por tanto, de ingresos. En esa misma cuerda se plantea la creación de una ley que regule esta forma de propiedad en diversos sectores y luego el cambio constitucional; una cuestión muy polémica es la referida al modelo escogido para reflejar como última ratio regum el cambio constitucional, que abordaremos posteriormente.

Se ha planteado igualmente la reampliación del trabajo por cuenta propia, aspirándose a que ocupe el $40 \%$ del volumen de la economía nacional ${ }^{54}$; en esta ampliación se derriba el límite establecido en la contratación de fuerza de trabajo y, además, se multiplica, por disposición del Consejo de Ministros, el número de actividades que podian realizarse, dándole mucha fuerza al concepto de oferta y demanda ${ }^{55}$ que en la mayoría de los casos asumirá el papel de mecanismo formador y regulador de los precios en el sector no estatal. Conectada con esta problemática está la indefensión jurídica en que se han colocado los asalariados en esta forma de gestión económica; no existe mecanismo legal que garantice, para este sector, conquistas históricas del movimiento obrero cubano y refrendadas en el orden legal insular como las ocho horas de trabajo, los derechos a la licencia de maternidad, las vacaciones pagadas, el descanso semanal, los feriados, la remuneración del trabajo conforme a su calidad y cantidad, el derecho a la sindicalización

52 Véase Lineamientos del 25 al 29 del texto finalmente aprobado.

53 Véase al respecto VI Congreso del Partido Comunista de Cuba. Lineamientos..., op. cit., p. 7.

54 Intervención especial del entonces ministro de Economía y Planificación, Marino MurILLO Jorge, en la Asamblea Nacional del Poder Popular con motivo de la aprobación por esta de los Lineamientos..., en diciembre de 2011.

55 Idem.

DÍKAION - ISSN 0120-8942 
y la justicia laboral ${ }^{56}$. Estas conquistas contribuyen a crear un mínimo sistema de garantías del asalariado frente su empleador lo que, unido a la prohibición de la concentración de la propiedad y a una efectiva política fiscal, puede mantener con limites bien precisos a esta forma de gestión.

No es posible renunciar a ello sin poner en peligro a la clase económica empoderada en Cuba: la trabajadora y, como consecuencia, colisionar con los postulados establecidos en el magno texto. La inexistencia de estas garantías a la larga no crea condiciones favorables para el desarrollo de la actividad que se pretende estimular, sino que atenta contra la seguridad jurídica del país y crea un escenario de peligro para el proyecto nacional.

Al respecto conviene volver a repasar el llamamiento al IV Congreso del Partido, convocado en un grave momento de la nación, cuando señalaba: "no se puede jugar irresponsablemente con mecanismos y categorías del capitalismo en pos de falaces y engañosas soluciones, que solo sirven para comprometer los objetivos de más largo plazo de la revolución y entronizar deformaciones y vicios" ${ }^{57}$, lo que tiene evidente consonancia con el mandato de la Constitución. El único límite que se argumenta, al menos más sólidamente, para estas categorías, radica en la política fiscal expresada en el lineamiento 59 que orienta "Estudiar la aplicación de estímulos fiscales que promuevan el desarrollo ordenado de las formas de gestión no estatal". En lo que se refiere a "ordenado", se puede colegir que ello significará un límite a determinadas actividades desarrolladas por el "cuentapropismo", sin embargo, el término "estímulos fiscales" marcha en un sentido terminológico visiblemente distinto.

Otra cuestión sería la volubilidad de la política fiscal que se erguiría como guardiana, vista desde este argumento, de todo el sistema. Nótese que en nuestro magno texto ni siquiera hay mención expresa al deber de contribuir. La doctrina financiera patria ha hecho ingentes esfuerzos por incluir dentro del artículo 34 la base de este deber al disponer que "los extranjeros residentes [...] se equiparan a los cubanos [...] en la obligación de contribuir a los gastos públicos en la forma y la cuantía que la ley establece", aquí el legislador-constituyente cometió un grave dislate al equiparar una obligación que ni siquiera tenian los nacionales ${ }^{58}$. Al margen de lo anterior no es posible proyectar, como se está haciendo, nuevas modificaciones al sistema tributario sin conectarlo con una Constitución urgida de actualización ${ }^{59}$.

56 Véase al respecto la Constitución de la República vigente que, en su artículo 45, segundo párrafo, consigna que: "El trabajo es remunerado conforme a su calidad y cantidad; al proporcionarlo se atienden las exigencias de la economía y la sociedad, la elección del trabajador y su aptitud y calificación; lo garantiza el sistema económico socialista...". Sin un sistema de garantías es imposible cumplir con lo antes preceptuado.

57 Partido Comunista de Cuba, Comité Central, “iAl IV Congreso del Partido!..., op. cit., p. 6.

58 Para mayor información remitimos al trabajo de la doctora Elena Polo MACEIRA, quien también abunda sobre el deber de contribuir y la trascendencia de su reconocimiento en el texto constitucional. Véase Elena Polo Maceira, Un sistema tributario cubano, de la realidad a la aspiración, Tesis para optar por el grado científico de Doctor en Ciencias Jurídicas, Santiago de Cuba, 2010.

$59 \mathrm{Al}$ respecto véase la información pública de la Reunión Ampliada del Consejo de Ministros celebrada el 31 de marzo de 2012. Donde se consigna que “...luego de los criterios emitidos por organismos e 
Un asunto espinoso es el nuevo tipo de propiedad que supone el trabajo por cuenta propia. Las seis formas de propiedad reconocidas por la Carta Magna son inconsistentes con esta nueva realidad social. Al inicio de la ampliación del trabajo por cuenta propia se argumentaba que era la propiedad personal la que regia este fenómeno; sin embargo, con la adopción de estas nuevas medidas, el segundo párrafo del artículo 21 resulta lapidario al sentenciar: "se garantiza la propiedad sobre los medios e instrumentos de trabajo personal o familiar, los que no pueden ser utilizados para la obtención de ingresos provenientes de la explotación del trabajo ajeno". Cualquier afirmación en contrario sería, ipso facto, inconstitucional. Aplicando la mayéutica socrática pudiéramos inquirir: ¿Qué tipo de propiedad es la que emerge de la "actualización del modelo económico"? La respuesta son las crónicas de un secreto a voces, nos encontramos ante el supuesto de la pequeña propiedad privada mercantil. Si se escogiera la politica del avestruz nos mantendríamos hablando de un concepto elástico e indeterminado de propiedad; contrario sensu, si nos determinamos por reconocer su necesidad y temporalidad, bien pudiésemos limitarla en el marco jurídico delineador de las principales relaciones económicas en el magno texto: la Constitución Económica, quedando claramente establecida en la Constitución la prohibición de la concentración de la propiedad, aunque el órgano legislativo sea el encargado de disponer ulteriores regulaciones para garantizar su observancia. No hacerlo es un acto irresponsable que pone en peligro la estabilidad del sistema y con él la legalidad socialista.

En caso de que se reconociese, el problema jurídico pudiera ocurrir a partir de la colisión de esta figura y la archirreferida cláusula pétrea, la que a posteriori abordaremos.

Debates al margen, los cambios relativos a la propiedad, que condicionan por su esencia el resto de los postulados de la Constitución Económica, no constituyen una simple "actualización" del modelo de gestión económica como popularmente se dice. No es posible, como ha señalado certeramente Lissette PÉrEz Hernández, sostener tal argumento cuando se colisiona poderosamente con la prohibición de la explotación del hombre por el hombre, característica esencial del socialismo. Se trata, pues, de una reforma al modelo ${ }^{60}$.

Otro tema sería la excesiva ponderación de este tipo de propiedad, pues se ha argumentado, con mucha fuerza, que con el proceso de "disponibilidad laboral" el sector asumiría gran parte de la fuerza de trabajo excedente; sin entrar en complejos ditirambos teóricos esta política también supone una contradicción fáctica con lo preceptuado por el constituyente. Al respecto no resulta ocioso recapitular la fórmula que planteara el IV Congreso del Partido:

instituciones como parte del proceso de su conciliación se realizaron adecuaciones al Anteproyecto de Ley del Sistema Tributario". Véase Periódico Granma, 81, Edición Única 48 (2012).

60 La connotación negativa del vocablo reforma, rechazado oficialmente, tiene un carácter marcadamente exegético, pues los movimientos reformistas en Cuba siempre tuvieron un signo menor de radicalidad; esta palabra se asocia a posiciones mediocres que, por ejemplo, preferían solicitar mejoras económicas a España en oposición a la independencia del país. Sin embargo, nos guste o no, es el término más adecuado para calificar el sostenimiento de un modelo con cambios trascendentes a su esencia. 


\begin{abstract}
"En los principios de la gestión empresarial debemos hallar la vía realista y práctica para encauzar la economía del país y fraguar, paso a paso, el sistema conveniente a nuestras necesidades. Este sistema se basará en el principio socialista de retribución y en la consagración comunista al trabajo. [...] Los intereses de la nación en su conjunto deberán prevalecer siempre sobre cualquier interés empresarial o sectorial”"61.
\end{abstract}

Esta vía fue ratificada por la Resolución Económica del V Congreso del Partido Comunista de Cuba al plantear: "como consecuencia de la contracción económica del periodo especial, se manifiesta un grado de subempleo que solo podrá ser superado gradualmente a partir de la reactivación de los niveles de actividad en el país"62. El cuentapropismo fue también ampliamente discutido y, conscientes de los riesgos que entrañaba una ponderación excesiva de esta forma de actividad laboral, al respecto se argumentaba: "en ciertas actividades, debido a las características de la producción o los servicios que se brindan podrá autorizarse por excepción cuando así convenga a los intereses del Estado que sean ejercidos por más de un trabajador en una misma instalación”63. La otrora excepción se ha convertido en regla.

Aunque existe un viejo axioma que pondera la esencia sobre la forma, en el ámbito jurídico la forma cobra una importancia cardinal. Hasta ahora la actualización del modelo económico se ha hecho dejando incólume el contenido constitucional, pretendiendo "arañar lo menos posible la Constitución". Ello implica una postergación de la reforma constitucional, lo que convierte el texto en una clase legitimadora del producto final de los cambios. En nuestro criterio, esta concepción niega el carácter transformador del derecho, suficientemente comprobado en nuestra historia reciente, baste con recordar las leyes de reforma agraria, urbana, las leyes de nacionalización, etc., todas ellas promulgadas antes de ocurrir los cambios que entrañaban. De este modo, la Constitución Económica perdería cierto vínculo con el objeto que regula, al no coincidir la constitución formal con la constitución material. Por ende, la Constitución Económica es incapaz de sustentar las nuevas relaciones económicas en el marco jurídico constitucional que ella encarna, agregándole al sistema económico social una dosis importante de inestabilidad. En este iter, la Asamblea Nacional del Poder Popular revisó y aprobó como líneas estatales los lineamientos ${ }^{64}$, suscitando una fuerte polémica en el marco de la competencia del propio órgano. Hasta para los no versados en derecho resulta contradictorio entender que el Parlamento, encargado por el constituyente en virtud del artículo 75, inciso c) del control constitucional al expresar: "Son atribuciones de la Asamblea Nacional del Poder Popular [...] decidir acerca de la constitucionalidad de las leyes, decretos-leyes, decretos y demás disposiciones generales”, aproba-

61 Partido Comunista de Cuba, Comité Central. “AAl IV Congreso del Partido!...”, op. cit., p. 9

62 Partido Comunista de Cuba, V Congreso, Resolución Económica del V Congreso del Partido Comunista de Cuba, en http://www.pcc.cu/congresos asamblea/cong5.php. Fecha de consulta: 12 de abril de 2012 .

63 Ídem., p. 16.

64 En este ámbito resulta curioso que el texto de los lineamientos definitivos publicados en mayo de 2011 ya declaraba que "los Lineamientos [...] son la expresión de la voluntad del pueblo, contenida en la política del Partido, el Estado y el Gobierno de la República de Cuba”, sin haber sido aprobados por la Asamblea Nacional del Poder Popular que solo lo hizo en diciembre del mismo año. 
se los lineamientos cuando estos contradecían abiertamente lo establecido en la Constitución Económica de la Carta Magna, con ello el referido órgano puso en entredicho la efectividad de esa importante facultad.

Otro criterio, a nuestro juicio erróneo, es el que manifiesta una suerte de "constitucionalidad instantánea” al argumentar la consonancia de los postulados partidistas a partir de la aprobación por el Parlamento. Este viene obligado a fallar siempre a favor de la Constitución, no se trata de decidir qué ley o decreto o disposición se ajusta a una determinada realidad, se trata de verificar su consonancia con lo dispuesto en la ley de leyes. Por ello, la lógica de reforma debe partir desde la cima legal, la Constitución, hacia las normas de inferior rango tomando como expresión modélica la pirámide kelseneana.

\section{El dilema de Paris. Una mirada a la Cláusula DE INTANGIBILIDAD A LA LUZ DE LA CONSTITUCIÓN ECONÓMICA}

Si en Hamlet el dilema shakesperiano residia en "ser o no ser...”, la cuestión que hoy nos plantea la dinámica de los cambios económicos en Cuba se puede concentrar en una frase corta y zahiriente: ¿Reforma o nueva constitución?

La piedra angular de este eje dicotómico radica en la cláusula de intangibilidad incorporada en la Reforma Constitucional de 2002, añadida al artículo tercero de la ley suprema al disponer:

\footnotetext{
"El socialismo y el sistema político y social revolucionario establecido en esta Constitución, probado por años de heroica resistencia frente a las agresiones de todo tipo y la guerra económica de los gobiernos de la potencia imperialista más poderosa que ha existido y habiendo demostrado su capacidad de transformar el país y crear una sociedad enteramente nueva y justa es irrevocable, y Cuba no volverá jamás al capitalismo".
}

Un párrafo antes concede el derecho de "combatir por todos los medios, incluyendo la lucha armada, cuando no fuera posible otro recurso contra cualquiera que intente derribar el orden político, social y económico establecido por esta Constitución" (énfasis agregado), con lo que se completa la visión sistémica-constitucional de la referida cláusula.

A partir de esta realidad se han enarbolado varios postulados teóricos. Por un lado, existe un grupo que defiende la imposibilidad de reformar en este aspecto la Constitución, toda vez que la inclusión de la propiedad privada, articulada en el conjunto de relaciones sociales como cuentapropismo, o las propias cooperativas, es contraria a la esencia del socialismo por constituir la célula más importante del capitalismo, sistema socioeconómico que el modelo socialista niega y supera. Existe un intento, desde la academia, de legitimar la inclusión de la propiedad privada de manera solapada bajo la redacción del artículo 15, posición que nos parece errada $a b$ initio, toda vez que obvia la hermenéutica sistémica de la Constitución. 
Sostener posiciones de este tipo implica un riesgo, a nuestro juicio, importantísimo, pues atenta contra la seguridad jurídica del orden económico.

En tal sentido, es clara la disposición del citado artículo 137 cuando establece:

"Esta Constitución solo puede ser reformada por la Asamblea Nacional del Poder Popular mediante acuerdo adoptado, en votación nominal, por una mayoría no inferior a las dos terceras partes del número total de sus integrantes, excepto en lo que se refiere al sistema político, social y económico, cuyo carácter irrevocable lo establece el artículo 3 del Capítulo I”65.

Esta cláusula, como especie de salvaguarda del legado originario del socialismo consagrado por el primer constituyente - al decir de la doctora Méndez LóPez- y entendida a la luz de la Constitución Económica, sobrepasa los límites con que histórica y teóricamente la podemos concebir, convirtiéndose en una verdadera cláusula pétrea que bien pudiéramos denominar de "inmutabilidad constitucional"66. La respuesta politica ${ }^{67}$ que representaba esta cláusula, junto al párrafo tercero del artículo 3, a la postre tendría grandes repercusiones para las cuestiones económicas en ella contenida.

Por tanto, concebir la propiedad privada dentro del sistema representa un choque frontal con la redacción actual y el espíritu originario del constituyente de 1976. De lo que podría colegirse que el ciclo histórico de la Constitución de 1976 ha concluido y se abre la opción de redacción de un texto nuevo que se conciba desde las nuevas realidades, que corporice los giros del proyecto nacional y que apunte hacia el futuro de la sociedad cubana.

En las antipodas de la posición anterior se encuentra otra que argumenta la posibilidad de continuar con los cambios, obviando la interpretación teleológica-sistémica del texto constitucional, pues desde este punto de vista la faceta económica no aparece expresamente consignada en la suprema norma en el artículo tercero, aunque sí en la cláusula de reforma.

Argumentos aparte, ambas proyecciones hermenéuticas representan un gran reto para la sociedad, la nación y el proyecto nacional. La primera interpretación, si bien defiende el cuerpo de la suprema ley, implica el reconocimiento de una forma de propiedad que a la larga representa una amenaza al sistema político, económico y social contenido en la carta de la nación. Desde este punto de vista, habría que redactar un magno texto, siempre con carácter provisional, que reconociese la pequeña propiedad mercantil privada mientras subsistiesen las circunstancias que obligaron a la adopción de tal medida. Huelga aclarar que la referida propiedad

65 Cuba, Constitución de la República, op. cit.

66 Término acuñado por los autores de este trabajo.

67 Esta modificación se origina en un momento de fuerte tensión entre el Gobierno cubano y el norteamericano, cuando este último exigió, mediante el Plan de Transición para una Cuba Libre, reformas al sistema político de la isla. La respuesta política se articuló mediante una proposición de las organizaciones sociales y de masas para aprobar la mencionada cláusula en el magno texto cubano. 
no entra en contradicción con el trabajo por cuenta propia, son categorías diferentes, solo que en el momento actual el marco que se ha creado para la ordenación de este último propicia abiertamente la aparición y el desarrollo de la primera.

El socialismo ha de seguir siendo la única vía para garantizar la soberanía política, social y económica de la nación, y con ello su existencia. En este o en el texto que se redacte esta idea ha de quedar bien clara; con las debidas consecuencias en materia de Constitución Económica. Al respecto, en 1995, MARTínez HEREDIA señaló:

"El tránsito más peligroso que tiene Cuba ante sí es la absolutización del proceso económico, que en las condiciones actuales llevaría al triunfo y al intento de legitimación del capitalismo. Ningún proceso de "restablecimiento" de la economía — por demás dilatado en el tiempo-, traería aparejado un florecimiento espontáneo del socialismo: eso no es posible ni ha existido en ninguna parte. La conservación de la soberanía nacional frente a los Estados Unidos solo será posible con un fuerte poder que represente efectivamente la voluntad de la nación, y ese mandato fue anudado a la sociedad de equidad elaborada a partir de 1959. Gue la representación social dominante sea anticapitalista es indispensable para que la cultura nacional pueda ser realmente una fuerza actuante y efectiva de unidad y de defensa de la sociedad y la nación. La renovación de las ideas socialistas se convierte, pues, en una necesidad" 68 .

Sobran los comentarios con esta sentencia.

Para estos autores resulta casi una obviedad que nuestra Constitución ha llegado al máximo de sus potencialidades, la válvula de seguridad contenida en el artículo 137 imposibilita cualquier movimiento en dirección de reformar el texto en materia de Constitución Económica. No se trata de cuestionar o no la añadidura de la cláusula pétrea sino de respetar lo contenido en ella, como garantía del respeto a la propia Constitución. Valdría recordar un axioma largamente repetido por un gran amigo nuestro: "A inicios de la Revolución la disyuntiva era, en aras de edificar la nueva sociedad: con la Revolución, todo; fuera de la Revolución, nada. Hoy, con el objetivo de preservar el proyecto revolucionario nacional, deberíamos asumir que con la Constitución, todo; fuera de la Constitución, nada”.

\section{CONCLUSIONES}

Si bien hemos afirmado supra que la Constitución ha llegado al máximo de sus posibilidades, también resulta prudente señalar que el camino hacia su actualización tiene escollos importantísimos. Inicialmente debemos calificar el nivel de actualización de acuerdo con su profundidad. Siguiendo esta línea de pensamiento, resulta obvia la existencia de dos escalones perfectamente delineados. Por tanto, en nuestro criterio, un primer paso consistiria en una reforma temporal

68 Fernando Martínez Heredia, En el horno de los noventa, op. cit., pp. 179-180.

DÍKAION - ISSN 0120-8942 
del magno texto que incluya, al menos, de manera provisoria algunas cuestiones básicas tales como:

- Inclusión de la mención expresa del deber de contribuir en el texto constitucional.

- De manera subsecuente con lo anteriormente expresado, la inclusión de los principios básicos del Derecho Tributario.

- Determinación y delimitación de las funciones de la Hacienda Pública en su concepción subjetiva.

- Establecimiento de la Contraloría General de la República como órgano superior de cuentas de las finanzas públicas en la nación.

- Extensión de la figura de las cooperativas a otros campos no agrícolas del tráfico jurídico económico, creando el marco regulador adecuado para la promulgación de la ley homónima.

Dado que en este paso no cabría la concepción actual del cuentapropismo, privado de sus limitaciones originarias, sería necesaria la redacción de un nuevo texto constitucional que, como hemos señalado, pueda brindar seguridad jurídica a las relaciones económicas que surjan en el marco de un panorama económico, político y social sustancialmente nuevo. Una clásica interrogante socrática resultaría del análisis del limbo jurídico en que quedaría esta categoría en relación con los pasos de reforma y construcción de un nuevo texto. En nuestro criterio, inexorablemente hay que afrontar ese riesgo, toda vez que ha quedado sumamente clara la imposibilidad de incluir dicha visión del trabajo por cuenta propia en los cánones de la Constitución de 1976.

Ahora bien, el contenido mínimo que proponemos para la reforma en el primer momento contribuye, al menos constitucionalmente, a limitar el alcance de esa nueva propiedad y, desde el punto de vista del Derecho Administrativo, se le proporciona desde la ley de leyes un marco jurídico de actuación a órganos que están constituidos hoy y son acreedores de una dudosa constitucionalidad, v. gr.: Contraloría General de la República, Oficina Nacional de Administración Tributaria. Otro asunto de no menor importancia es el reconocimiento de las cooperativas no agrícolas, puesto que se ampliaría subjetivamente, desde la Constitución, el tráfico jurídico. Un segundo momento lo constituiría la redacción de una nueva carta magna. Sin embargo, es imprescindible, al objeto del estudio de la Constitución Económica, proyectar las bases que en esta materia debería contener el eventual texto.

Sin lugar a dudas, este será hijo legitimo del nuevo constitucionalismo latinoamericano y de las ideas iusfilosóficas que se insertan en esta corriente revolucionaria. Su existencia permitirá la real defensa institucional del proyecto nacional, dotará de seguridad jurídica a las transformaciones que en materia económica 
se desarrollan en la isla, y abrirá las puertas a un nuevo ciclo constitucional en nuestra República Socialista. Ello, más que un capricho de legistas, se convierte en una urgencia histórica, iniciarlo es un acto que corresponde al legado de nuestra nación, un episodio más en este combate de casi seis centurias por nuestra independencia. No pretendemos ilustrar sobre el proceso orgánico necesario para llegar a la constituyente, elemento per se controversial, solo aspirar a que se realice con la fórmula que presidió el proyecto martiano de nación: "con todos y para el bien de todos”.

\section{BIBLIOGRAFÍA}

\section{Libros}

AA.VV., Apuntes de Derecho Financiero Cubano, La Habana, Editorial Félix Varela, 2005.

AA.VV., Jornadas Colombo-Venezolanas de Derecho Público, Bogotá, Departamento de Publicaciones de la Universidad Externado de Colombia, 1996.

AA.VV., Monopolios norteamericanos en Cuba. Contribución al estudio de la penetración imperialista, Horacio García Brito (ed.), La Habana, Editorial de Ciencias Sociales, 1973.

AA.VV., Panorama de la Ciencia del Derecho en Cuba. Estudios en homenaje al profesor Dr. C. Julio Fernández Bulté, La Habana, Lleonard Muntaner, 2009.

AA.VV., Temas de derecho agrario cubano. Selección Legislativa de Derecho Agrario Cubano, La Habana, Editorial Félix Varela, 2007.

Acosta Iparraguirre, Vicente, La Constitución Económica en el Perú y en el derecho comparado, tesis para optar por el Grado Académico de Doctor en Derecho. Universidad Nacional Mayor de San Marcos, Lima, Perú, 2003, en http://sisbib.unmsm.edu.pebibvirtualdataTesisHumanAcosta_I_VT_completo.pdf. Fecha de consulta: 20 de enero de 2012 .

Álvarez Conde, Enrique, Curso de Derecho Constitucional, vol. I, El Estado Constitucional. El Sistema de fuentes. Los derechos y libertades, 4 ed., Madrid, Tecnos, 2003.

Álvarez Conde, Enrique, Curso de Derecho Constitucional, vol. II, Los órganos constitucionales. El Estado Autonómico, 4 ed., Madrid, Tecnos, 2000.

Álvarez Tabí, Fernando, Comentarios a la Constitución Socialista, La Habana, Editorial Ciencias Sociales, Ediciones Jurídicas, 1981.

Bassols Coma, Martín, Constitución y sistema económico, Madrid, Tecnos, 1988.

CARreras, Julio A., Historia del Estado y el Derecho en Cuba, La Habana, Ministerio Educación Superior, 1981.

CASTRo, Fidel, "La historia me absolverá”, en 7 Documentos de Nuestra Historia, La Habana, Editora Politica, 1967. 
Costales P., Marcela. Alfonso de Illescas. El Gobernador Negro, Quito, Presidencia de la República, Secretaría de Pueblos, Movimientos Sociales y Participación Ciudadana, Colección Generala Manuela Sáenz, (s. f.).

Denisvo Kirichenko, A. y M. La Ley del Estado soviético, Moscú, Foreign Languages Publishing House, 1960.

ERHARD, Ludwing, Economía Social de mercado. Su valor permanente, Madrid, Rialp, 1994.

Espinoza Rausseo, Alexander, Derecho Constitucional en Alemania y Austria. Principios de la Constitución. Derechos fundamentales, Caracas, 1997.

Fernández Bulté, Julio, Filosofia del Derecho, La Habana, Editorial Félix Varela, 2005.

Fernández Bulté, Julio, Historia del Estado y el Derecho en Cuba, La Habana, Editorial Félix Varela, 2005.

Fernández Bulté, Julio, Siete Milenios de Estado y de Derecho, La Habana, Editorial Ciencias Sociales, 2008.

Fernández Bulté, Julio, Teoría del Estado y el Derecho. Teoría del Derecho, La Habana, Editorial Félix Varela, 2004.

Foner, Philip S., Historia de Cuba y sus relaciones con Estados Unidos, tomos 1 y 2, La Habana, Editorial de Ciencias Sociales, 1973.

Font Galán, Juan Ignacio, Constitución Económica y Derecho de la Competencia, Madrid, Tecnos, 1987.

Foucault, Michel, Nacimiento de la Biopolitica, Madrid, Akal, 2009.

Franco, José Luciano, Ensayos Históricos, La Habana, Editorial Ciencias Sociales, 1974.

FRIEDRICH, Carl J., Teoría y realidad de la organización constitucional democrática, México: Fondo de Cultura Económica, 1946.

Fundación Konrad Adenauer, Derechos Humanos, Estado de Derecho, Desarrollo Social en Latinoamérica y Alemania, Caracas, Horst Shönbohm, 1994.

Galeano, Eduardo, Patas Arriba. La escuela del mundo al revés, La Habana, Editorial Cajachina, Colección Patas Arriba, 2009.

García Belaúnde, Domingo, Teoría y práctica de la constitución peruana, tomo II, Lima, Ediciones Justo Valenzuela, 1993.

García del Pino, César, Toma de La Habana por los ingleses y sus antecedentes, La Habana, Ciencias Sociales, 2002.

García Pelayo, Manuel, "Consideraciones sobre las cláusulas económicas en la Constitución”, en Obras Completas, tomos I-III, Madrid, Centro de Estudios Constitucionales, 1991.

George, Susan, Otro mundo es posible si..., La Habana, Editorial Ciencias Sociales, 2002. 
Gómez Ferrer, Juan Gualberto, Por Cuba Libre, La Habana, Editorial de Ciencias Sociales, 1974.

Grocholewski, Zenón, La Filosofia del Derecho en las enseñanzas de Juan Pablo II y otros escritos, Bogotá, Temis S.A., Instituto de Humanidades, Universidad de La Sabana, 2001.

Guiteras Holmes, Antonio, Antonio Guiteras. Su pensamiento Revolucionario, Olga Cabrera (Selección y estudio introductorio), La Habana, Editorial de Ciencias Sociales, 1974.

Hauriou-Jean Gicguel, André y Patrice Gelard, Derecho Constitucional e Instituciones politicas, con apéndice sobre la Constitución Española de J. A. González Casanova, Barcelona, s. e., 1980.

Herrera de Miñón, Miguel, "La Constitución Económica", en Material de Maestría en Derecho Empresarial. Derecho Empresarial. Derecho Constitucional Económico, tomo II, Lima, Universidad de Lima, Facultad de Derecho y Ciencias Politicas, s. f.

Hoppe, Hans-Hermann, "From the Economics of Laissez Faire to The Ethics of Libertarianism", en Man, Economy, and Liberty. Essays in Honor of Murray N. Rothbard, Auburn: The Ludwig von Mises Institute, Auburn University, 1988.

Laski, Harold, Historia del Liberalismo Europeo, Madrid, Tecnos, 1984.

Lazcano y Mazón, Andrés María, Las Constituciones de Cuba, Madrid, Ediciones Cultura Hispánica, 1952.

Le Riverend Brusone, Julio, Historia Económica de Cuba, La Habana, Edición Revolucionaria, 1981.

Le Riverend Brusone, Julio, Historia Económica de Cuba, La Habana, Instituto del Libro, 1967

Le Riverend Brusone, Julio et al., Historia de Cuba, tomos 1-6, La Habana, Editorial Pueblo y Educación, 1974-1978.

Loza Macías, Manuel, El pensamiento económico y la Constitución de 1857, México: Congregaciones Marianas, 1984.

Márguez Sterling, Manuel, La diplomacia en nuestra historia, La Habana, Instituto del Libro, 1967.

Martí, José y Máximo Gómez, "Manifiesto de Montecristi”, en 7 Documentos de Nuestra Historia, La Habana, Editora Política, 1967.

Martínez Heredia, Fernando, En el horno de los noventa, La Habana, Editorial Ciencias Sociales, 2005.

Martínez Villena, Rubén, Cuba, factoría yanqui, La Habana, Editorial de Ciencias Sociales, 1999.

Marx, Carlos y Federico Engels, "Manifiesto del Partido Comunista", Obras escogidas en dos tomos, tomo I, Moscú, Editorial Progreso, 1971. 
Peces-Barba Martínez, Gregorio y Miguel Ángel Ramiro Avilés (coords.). La Constitución a examen: un estudio académico 25 años después, Madrid, Instituto de Derechos Humanos Bartolomé de las Casas, Marcial Pons, 2004.

Pedrol, Xavier y Gerardo Pisarello, La Constitución europea y sus mitos: una crítica al tratado constitucional y argumentos para otra Europa, Madrid, Icaria, 2005.

Pichardo Viñals, Hortensia, Documentos para la historia de Cuba, tomo I, La Habana, Editorial de Ciencias Sociales, 1980.

Rodríguez García, José Luis, et al., Revolución Económica 1959-1960, La Habana, Editorial Ciencias Sociales, 1985.

Roig De Leuschering, Emilio, Historia de la Enmienda Platt, La Habana, Editorial de Ciencias Sociales, 1973.

Roig de Leuschering, Emilio, La Habana. Apuntes históricos, La Habana, Editora del Consejo Nacional de Cultura, Colección Documentación Histórica, 1964.

Roig De Leuschering, Emilio, Marti antimperialista, 2 ed., La Habana, Ministerio de Relaciones Exteriores, 1961.

SAco, José Antonio, José Antonio Saco. Contra la anexión, Fernando Ortiz (recopilación, prólogo y ultílogo), La Habana, Editorial de Ciencias Sociales, 1974.

Sainz de Bujanda, Fernando, Lecciones de Derecho Financiero, Madrid, Facultad de Derecho de la Universidad Complutense de Madrid, 1991.

Schmiтt, Carl, Der Hüter der Verfassung, Madrid, Leitartikel Tecnos, 1983.

VANGBERG, Viktor, Racionalidad y Reglas. Ensayos sobre la teoría económica de la Constitución, Barcelona, Gedisa, 1999.

República Bolivariana de Venezuela. Vicepresidencia, Breve reseña histórica de las constituciones de Venezuela de 1811 a 1999, Caracas, Instituto Municipal de Publicaciones, Alcaldía del Municipio Libertador, 2000.

Vicente Aguilera, Francisco, Epistolario, Marta Cruz y Olimpia López Laurel (Recopilación documental) La Habana, Editorial de Ciencias Sociales, 1974.

Vizcaino, L., et al., Apuntes para la historia del movimiento juvenil comunista y pioneril cubano, La Habana, Editora Política, 1987.

\section{Artículos, monografías y publicaciones seriadas}

BiAsco, Emilio, La Constitución Económica en la Constitución Uruguaya, Universidad de la República, Facultad de Ciencias Económicas y de Administración, Cátedra de Derecho Público, Materiales, Montevideo, 2010, en http://www. ccee.edu.uy/ensenian/catderpu/material/2010/La Constitucion_uruguaya. pdf. Fecha de consulta: 24 de febrero de 2012.

Bidart Campos, Germán, "La Constitución Económica (Un esbozo desde el Derecho Constitucional argentino)", en Cuestiones Constitucionales, 6 (2002) en http://redalyc.uaemex.mx/pdf/885/88500601.pdf. Fecha de consulta: 19 de enero de 2012. 
Brewer-CARÍAs, Allan R., "Reflexiones sobre la Constitución Económica". En Revista de Derecho Público, 43 (1990), en http://www.ulpiano.org.ve/revistas/ bases/artic/texto/RDPUB/43/rdpub_1990_43_5-16.pdf. Fecha de consulta: 20 de enero de 2012.

Cancio Melí, Jorge, "La Constitución económica: promesas incumplibles", en Revista Jurídica de la Universidad Autónoma de Madrid, 7 (2002), pp. 49-101. en www.uam.es/personal_pdi/.../cancio_constitucioneconomica.doc. Fecha de consulta: 17 de febrero de 2012.

Castillo Cadena, Fernando, La Constitución Económica Boliviana: una óptica desde la Universidad Colombiana, Bogotá, Facultad de Ciencias Jurídicas, Pontificia Universidad Javeriana, 2010. [En línea]. Fecha de consulta: 19 de enero de 2012.

CAstro Ruz, Fidel, Discurso pronunciado por el Comandante Fidel Castro Ruz, Primer Secretario del Comité Central del PCC y Primer Ministro del Gobierno Revolucionario, en el Acto Central por el 1ro de mayo de 1971, en http:// www.cuba.cu/gobierno/discursos/1971/esp/f010571e.html. Fecha de consulta: 11 de abril de 2012 .

Coladic-RD, Reseña Coloquio Jurídico La Constitución Económica, en http://www. coladic-rd.org/cms/wp-content/uploads/2008/07/resena_cj_const_ec.pdf. Fecha de consulta: 18 de enero de 2012.

Cuba, Asamblea Nacional del Poder Popular, Tercera Legislatura, Actas Décimo Primer Período Ordinario de Sesiones, 1992.

CuBA, CC PCC, “¡Al IV Congreso del Partido! ¡El futuro de nuestra patria será un eterno Baraguá!”, en Periódico Granma, 18 de marzo de 1990.

Cuba, Partido Comunista de Cuba, V Congreso, Resolución Económica del V Congreso del Partido Comunista de Cuba, en http://www.pcc.cu/congresos asamblea/ cong5.php. Fecha de consulta 12 de abril de 2012.

Cuba, Partido Comunista de Cuba, VI Congreso del Partido Comunista de Cuba. Lineamientos de la política económica y social del Partido y la Revolución, 18 de abril de 2011.

FERNÁNDEZ, Ángel, Constitución económica como instrumento para limitar el estatismo, en http://www.juandemariana.org/comentario/3340/constitucion/economica/instrumento/limitar/estatismo/. Fecha de consulta: 13 de marzo de 2012.

Ferney Moreno, Luis, “Teorías de la Constitución Económica”, en Contexto: Revista de Derecho y Economía, Bogotá, Publicaciones Universidad Externado de Colombia, 2000, en http://portal.uexternado.edu.co/irj/go/km/docs/documents/UExternado/pdf/5_revistaContexto/Contexto/Archivo/Contexto\%207/ LuisFerneyMoreno.pdf. Fecha de consulta: 10 de febrero de 2012.

Ferrada Bórguez, Juan Carlos, "La Constitución Económica de 1980, Algunas reflexiones criticas”, Revista de Derecho, XI (2000), en http://mingaonline. uach.cl/pdf/revider/v11/art05.pdf. Fecha de consulta: 19 de enero de 2012. 
García Ruiz, José Luis, Algunas reflexiones sobre la Constitución Económica y el estado autonómico (Versión provisional), en http://www.estig.ipbeja.pt/ ac_ direito/JoseLuisGarcia.pdf. Fecha de consulta: 19 de enero de 2012.

Laurent, Eloy y Jacques Le Cacheux, "What (Economic) Constitution Does "the EU Need?”, en Document de Travail, 04 (2007). Observatoire Fran ois des Conjonctures Économiques, en http://www.ofce.sciences-po.fr/pdf/dtravail/WP200704.pdf. Fecha de consulta: 3 de febrero de 2012.

Maestro Buelga, Gonzalo, Estado de Mercado y Constitución Económica: algunas reflexiones sobre la crisis constitucional europea, Proyecto Gobernanza económica y Constitución económica, Ministerio de Educación y Ciencia. Referencia SEJ 2004-o7987, en http://www.ugr.es/ redce/REDCE8/ articulos/02MaestroBuelga.htm. Fecha de consulta: 13 de marzo de 2012.

Magliulo, Antonio, La Costituzione Economica dell'Italia nella Nuova Europa. Un'interpretazione Storica, en http://www.mps.it/NR/rdonlyres/1C20853367AF-4032-9FD1-8FAE028E4135/34360/16_magliulo.pdf. Fecha de consulta: 20 de marzo de 2012.

Molina, Jerónimo, Sin ilusión, sin pesimismo. El realismo político liberal de Raymond Aron, en http://www.fundacionfaes.org/record_file/filename/20/00004-10_-_ sin_ilusion_sin_pesimismo_el_realismo_politico_liberal.pdf. Fecha de consulta: 24 de enero de 2012.

Monroe SuÁrez, José, "La Constitución Económica Peruana”, Revista DECIR, 1-1 (2010), en http://www.utp.edu.pe/userfiles/file/DERECHO/ RDECIR/02RD11Monroe.pdf. Fecha de consulta: 3 de febrero de 2012.

Nogueira Alcalá, Humberto, "Los derechos económicos, sociales y culturales como derechos fundamentales efectivos en el constitucionalismo democrático latinoamericano", en Estudios Constitucionales, 7-2 (2009), pp. 143-205.

Nolte, Detlef, Reformas Constitucionales en América Latina en perspectiva comparada: la influencia de factores institucionales (Versión preliminar), German Institute of Global and Area Studies (GIGA), 2011, en http://www.cide.edu/ programas/SE_PYG_2011-03_Nolte_Reformas_constitucionales.pdf. Fecha de consulta: 14 de marzo de 2012.

OEA, Situación de los Derechos Humanos en Cuba. Séptimo Informe. Ser. L/V/ II.61. Doc.29 rev. 14 octubre 1983, en http://www.cidh.org/countryrep/Cuba83sp/capitulo10.htm. Fecha de consulta: 11 de abril de 2012.

PAK-KWAN, Chau, "Economic Constitucionalism in the China Circle: Comparative Economic Provisions in the Constitutions of Mainland China, Taiwan and Hong Kong”, en Law and Governance in the Developing World, April, 1998, en http:/ /echaupak.net/thesis/ecocon.pdf. Fecha de consulta: 3 de febrero de 2012.

PAtiño CASTRo, Iván, “Clasificación de las normas constitucionales”, Revista Jurídica Online (2004), en http:/ /www.revistajuridicaonline.com/images/stories / revistas/2004/17/17_Clasificacion_Normas_Constitucionales.pdf. Fecha de consulta: 6 de marzo de 2012 . 
Peñalver, Luis R., La formación de la encomienda en el valle de Cumanacoa, nol. 21, núm. 81, México DF, s. e., 2003.

PERnA, Raffaele, L'Italia ha bisogno di una nuova Costituzione Economica?, en http://www.astrid-online.it/La-Costitu/Studi--ric/L-Italia-h/Perna-R_Incontro_fondazione-Magna-Carta_15_06_10.pdf. Fecha de consulta: 1 de marzo de 2012 .

Ramirez Arrayás, José Antonio, Constitución económica y dominio legal, en http:// www.estig.ipbeja.pt/ ac_direito/JoseAntonioRamirez.pdf. Fecha de consulta: 18 de enero de 2012.

Ramírez Vera, Douglas, "Los modelos de toma de decisión en lo político: armonía y conflicto, y asignación en lo económico: mercado y jerarquía. Elementos para un debate", Economía, 19/20 (2003/2004), pp. 87-108, en http://www.saber. ula.ve/bitstream/123456789/19248/2/articulo4.pdf. Fecha de consulta: 24 de enero de 2012.

Reinaldo VAnossi, Jorge, "La aplicación constitucional de 'El Análisis Económico del Derecho (AED)': ¿Nada menos y nada más que un 'enfoque'? Comunicación del académico Jorge Reinaldo Vanossi en sesión privada de la Academia Nacional de Ciencias Morales y Políticas, el 9 de abril de 2008”, en Anales de la Academia Nacional de Ciencias Morales y Politicas. Doctrina, 2008, en http://www.ancmyp.org.ar/user/files/02Vanossi.pdf. Fecha de consulta: 20 de enero de 2012.

Ricart Martí, "Encarnación. Situación jurídica del individuo en relación con la libertad y la ciudadanía en Derecho Romano. Una visión del siglo XXI”, en Revista Res pública litterarum, Serie Documentos de Trabajo del Grupo de Investigación "NOMOS”, Madrid, Universidad Carlos III de Madrid, Instituto "Lucio Anneo Séneca”, 2005, en http://docubib.uc3m.es/WORKINGPAPERS/ IECSPA/iescpA050101.pdf. Fecha de consulta: 12 de enero de 2012.

Rodríguez, Javier, La Constitución Económica, en http://www.gestiopolis.com/recursos/documentos/fulldocs/eco/deryconstieco-1.htm. Fecha de consulta: 19 de marzo de 2012.

VAldÉs SÁnchez, Servando, "Fulgencio Batista. Del septembrismo a la alternativa militarista”, en Calibán (2009), en http://www.revistacaliban.cu/articulo. php?article_id=23\&numero=2. Fecha de consulta: 4 de abril 2012.

VAngberG, Viktor J., "Mercados y regulación. El contraste entre el liberalismo de libre mercado y el liberalismo constitucional", en Revista Isonomia, 17 (2002), en http://bib.cervantesvirtual.com/servlet/ SirveObras/01372764235795943200024/isonomia17/isonomia17_04.pdf. Fecha de consulta: 20 de enero de 2012.

Woods, Allan, Stalin 50 años después de la muerte del tirano, en http: / /www.fundacionfedericoengels.org/index.php?option=com_content $\&$ view=article\&id=1 12: stalin-50-anos-despues-de-la-muerte-del-tirano\&catid=43:cuaderno-deformacion-marxista-no-7\&Itemid=63. Fecha de consulta: 11 de abril de 2012 . 
WörsDörfer, Manuel, "Ordoliberalism and the Evolution of Norms", Normative Working Paper, Frankfurt, Goethe University, 2010, en http://www.google. com.cu/url?sa=t\&rct=j\&q=Wettbewerb+und+Monopolkampf $+*+$ Carl+Schmit t\&source=web\&cd=10\&ved=0CGEQFjAJ\&url=http $\% 3 \mathrm{~A} \% 2 \mathrm{~F} \% 2 \mathrm{Fpublikation}$ en.ub.uni-frankfurt.de\%2Ffiles\%2F20467\%2FOrdoliberalism_and_the_Evolution_of_Norms.pdf\&ei=u_VHT6HrM8fq0gGY47CWDg\&usg=AFQjCNEKkfDEwjC 5trTzQc82WcmQMmwxlw\&cad=rja. Fecha de consulta: 24 de febrero de 2012.

\section{Legislaciones y Jurisprudencia}

Cuba, Asamblea Nacional del Poder Popular, Ley 107 de la Contraloría General de la República de Cuba, en Gaceta Oficial de la República de Cuba, 029 (2009).

Cuba, Asamblea Nacional del Poder Popular, ley 54 - Ley de Asociaciones, en http://www.parlamentocubano.cu/index.php?option=com_ content\&view=article\&id=268:ley-no-54-ley-de-asociaciones\&catid=46:leyes \&Itemid=79. Fecha de consulta: 11 de abril de 2012 .

Cuba, Comisión Redactora, “Constitución de la República de Cuba de 1976”, en Selección legislativa de Derecho Constitucional, La Habana, Editorial "Félix Varela”, 2004.

Cuba, Consejo de Estado, Decreto-Ley 14 - Sobre el ejercicio de actividades laborales por cuenta propia de 3 de julio de 1978, Archivo Digital de la Biblioteca de la Asamblea Nacional del Poder Popular.

Cuba, Consejo de Estado, Decreto-Ley 274 de 30 de septiembre de 2010, Modificativo del Decreto-Ley 174/97, "De las contravenciones personales de las regulaciones del trabajo por cuenta propia”, Archivo Digital de la Biblioteca de la Asamblea Nacional del Poder Popular.

Cuba, Convención Constituyente, Ley 1 - Constitución de la República de Cuba, Gaceta Oficial de la República de Cuba, 464, Año XXXVIII, tomo VII, vol. II, 8 de julio de 1940.

Cuba, Ejército Libertador, "Papelería del jefe de la 2 da brigada de la 1 a - División del ler Cuerpo del Ejército”, Colección de Leyes, Acuerdos Legislativos y Disposiciones Gubernativas más importantes, en Archivo Nacional de Cuba, Legajo 473, núm. 2 , s. f.

Cuba, Presidente de la República de Cuba, Ley de Reforma Urbana, 14 de octubre de 1960, Gaceta Oficial de la República de Cuba, Edición Extraordinaria, Año LVIII, tomo quincenal XIX.

República de Cuba en ARmas, Consejo de Gobierno, "Resolución del Consejo de Gobierno de fecha 16 de septiembre de 1896”, en La Independencia, 25-II (1896). 


\section{Otras}

Comité Central del Partido Comunista de Cuba, Departamento de Organización, Archivos.

Polo Maceira, Elena. Un sistema tributario cubano, de la realidad a la aspiración, Tesis para optar por el grado científico de Doctor en Ciencias Jurídicas, Santiago de Cuba, 2010.

PRIETo VAldÉs, Martha. El Derecho, la Constitución y su interpretación, Tesis para optar por el grado científico de Doctor en Ciencias Jurídicas, La Habana, mayo del 2002. 